Preprints of the

Max Planck Institute for

Research on Collective Goods

Bonn 2015/20

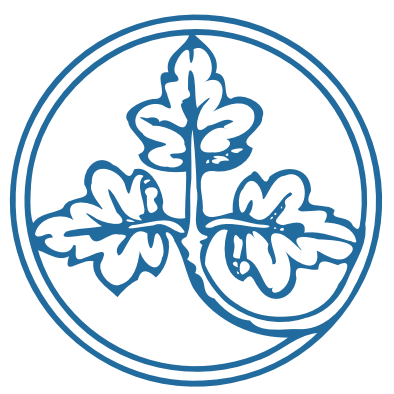

Beyond Information:

Disclosure, Distracted Attention, and Investor

Behavior

Adrian Hillenbrand

André Schmelzer

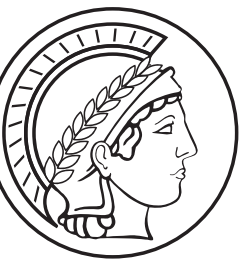




\section{Beyond Information: Disclosure, Distracted Attention, and Investor Behavior}

Adrian Hillenbrand / André Schmelzer

December 2015 


\title{
Beyond Information: Disclosure, Distracted Attention, and Investor Behavior*
}

\author{
Adrian Hillenbrand André Schmelzer
}

Working paper version: December 2015

\begin{abstract}
Financial disclosure documents provide investors with product details to facilitate informed investment decisions. We investigate whether the appearance - the visual frame - of disclosure documents impacts risk and return expectations and investment behavior. In our experiment, subjects decide about investments into real-life mutual funds. We find that subjects expect a smaller return variance, invest more and gather less correct information if visual distractors are present in the visual frame. Results are in line with the distracted attention mechanism and suggest that disclosure policies should take the visual frame into account.
\end{abstract}

JEL classification: C91, D03, D14, D18, D84

Keywords: Portfolio choice, experiment, disclosure, mean-variance theory, attention.

*We thank Christoph Engel, Minou Ghaffari-Tabrizi, Thomas Hettig, Jens Prüfer, Franziska Tausch, Martin Weber, and the audiences and seminar participants at the Max Planck Institute for Research on Collective Goods, Bonn, ESA European meeting Heidelberg 2015, IMPRS Ringberg 2015, CLEEN Tilburg 2015, and Experimental Finance Nijmegen 2015 for helpful comments. We gratefully acknowledge financial support from the Max Planck Society for the Advancement of Science. The authors declare that they have no relevant or material financial interests that relate to the research described in this paper.

${ }^{\dagger}$ Max Planck Institute for Research on Collective Goods; Bonn Graduate School of Economics, University of Bonn. email hillenbrand@coll.mpg.de.

${ }_{\ddagger}^{\ddagger}$ Max Planck Institute for Research on Collective Goods, Kurt-Schumacher-Str. 10, D-53113 Bonn, Germany. email schmelzer@coll.mpg.de 


\section{Introduction}

Good investment decisions require the consideration of relevant information. However, processing this information is a demanding exercise. Most investors have limited capacities for handling it. Providing information in disclosure documents can help facilitate access to and reception of pertinent information.

One regulatory response to the financial crisis of 2007-08 was aiming at improving consumer financial decision-making by simplifying disclosures (see also Campbell et al., 2011). More precisely, key investor documents (henceforth KIDs) were introduced as a requirement for investment funds (UCITS 2009/65/EC). These mandatory documents aim at increasing understandability and comparability of financial products for retail investors. Present rules regulate content and structure of the information document.

Loewenstein, Sunstein and Golman (2014) highlight the role of attention in decisionmaking based on information disclosures. They state that psychological factors such as limited attention can severely undermine the efficacy of disclosure as a public policy. Bhargava and Loewenstein (2015) argue that policy makers should protect consumers from firms exploiting their inattention.

If attention is key, we claim that the visual frame of disclosure documents becomes crucial. We define visual frame as the frame encompassing information which does itself not contain additional informational value about the product. This visual frame could include visual distractors. Visual distractors are parts of the frame that distract attention from the content of the document. These could be banners or colors in the document. Attention is prone to distraction in tasks requiring a high working memory load (mental effort), such as reading disclosures (de Fockert et al., 2001; Lavie et al., 2004). By distracting attention, the visual frame could impact decision-making.

In this paper we investigate whether standardizing the visual frame of disclosures impacts risk and return expectations and investment behavior. We standardize the visual frame by removing visual distractors. We employ a between-subjects design. In our experiment, we compare investments in real-life mutual funds based on original documents (original) with investments based on standardized documents (neutral). This allows us to infer a causal relation from changing the visual frame of disclosures on investment behavior.

We find that investments are significantly higher if visual distractors are present in the document. Further, we elicit beliefs about expected returns. While expected values are on average similar in both treatments, expected variance of returns is found to be significantly smaller for investors facing visual distractors.

We pin down mechanisms underlying this behavior. Our theoretical framework of Bayesian 
updating encompasses two psychological mechanisms: distracted attention and reinforced familiarity. Results favor distracted attention as the main mechanism. Individuals spent more time acquiring more correct information when reading standardized documents. The documents are perceived as equally informative, i.e., subjects reading the original documents are not aware that they capture less information.

Importantly, we find no evidence for familiarity interacting with the treatment variation. In particular, we find no larger treatment differences concerning expected rate of return and investments for familiar firms. But if our results were driven by a mere 'marketing effect', we would expect this interaction. Accordingly, familiar firms would attract higher investments from including visual distractors such as logos (e.g., Hoeffler and Keller, 2003). In fact, we find the largest treatment effect for an unfamiliar firm. Also, we do not find treatment differences in trust and reliability perception of the documents.

The main contribution of this paper is to provide experimental evidence that the visual frame itself impacts expectations and choice behavior by distracting attention. Recent literature finds that changing information in the document influences investment behavior (Bertrand et al., 2010; Bertrand and Morse, 2011; Beshears et al., 2014). In this paper, we go further. To the best of our knowledge, this is the first experimental paper in the domain of financial decision-making to change the visual frame, while holding information constant.

Our work is related to the financial decision-making and portfolio choice literature. In particular, we contribute to the literature on determinants of mutual fund investment behavior. Here, it is commonly found that individuals do not invest optimally. Current research finds that mutual fund investors disregard costs (Barber et al., 2006; Pontari et al., 2009, Choi et al. 2010). Investors rather focus on past returns of the funds, which relates to the behavioral hot hand effect (Hendricks et al., 1993; Sapp and Tiwari, 2004). Sirri and Tufano (1998) regard search costs to be a major determinant of investment behavior. Search costs are argued to explain general advertising effects in the mutual fund market (Sirri and Tufano, 1998; Jain and Wu, 2000; Cronqvist, 2006; Koehler and Mercer, 2009; Lee et al., 2012). Firms selectively advertising high-performing funds are found to be treated as representative by individuals (Koehler and Mercer, 2009).

One particular line of literature focuses on the impact of changing the quality of information by presenting it in different formats. There is evidence that individuals focus on graphical and salient information (Jarvenpaa, 1989, 1990). Kaufmann et al. (2013) find that the format quality of risk information influences fund investment decisions. Perception of risk information in graphical presentations is also found to impact portfolio choice by the degree of aggregation of risk and return information (Kaufmann and Weber, 2013). In line with these findings, de Goeij et al. (2014) claim that graphical representation of risk and 
return may also have a debiasing effect. Weber et al. (2005) find that the presentation format of historical returns and asset name familiarity impact expectations.

A second line of literature focuses on the effect of changing the quantity of information by comparing short and long disclosures. In particular, there is evidence specifically on KID disclosure documents. Results on the impact of a decreasing quantity of information on mutual fund choice are mixed. Beshears et al. (2011) find that there is no effect on portfolio choice comparing short and long disclosures. In contrast, Walther (2015) finds that there is a positive effect of short information on perceived information quality and a negative impact on information overload. The findings of Kozup et al. (2008) on short disclosures are consistent with the literature on mutual funds. That is, investors are found to discard costs and to focus on historical information.Again, we depart from both lines of literature. We do not change information, but the visual frame.

In order to standardize the documents we remove visual distractors such as logos, banners and colors. In our sample of funds these are connected to the firm and can be understood as marketing instruments. The literature on advertisement provides studies about effectiveness of the use of logos (e.g., Park et al., 2013). These works suggest differences in optimal decisions, e.g., in logo placement based on the familiarity of the brand (e.g., Sundar and Noseworthy, 2014). This is part of a broader literature discussing how brand familiarity ("brand equity") interacts with marketing efficacy (see e.g., Baker et al., 1986; Tuominen, 1999; Aaker, 2009; Stahl et al., 2012). One result is that higher brand familiarity increases the effectiveness of marketing instruments. We capture these insights in our 'reinforced familiarity' assumption. However, we find no evidence for this effect. This suggests that in our context there are no additional gains from having a more familiar brand.

From a policy perspective, our results indicate that the visual frame needs to be considered in designing disclosure policies. On behalf of the European Commission (EC), specific KID testings have been carried out (IFF Research and YouGov, 2009). The report indicates that individuals prefer a risk indicator, ten years of past performance in a bar chart, and costs displayed in a separate table. These suggestions have been implemented in disclosure policies. The report of Chater et al. (2010), also prepared for the EC, provides representative experimental evidence across EU countries that retail investors are prone to biases and do not decide optimally. However, both reports are silent about the visual frame.

The remainder of this paper is organized as follows. Section 2 introduces the theoretical Bayesian framework and the experimental hypotheses. Our experimental design and the treatment variation is explained in section 3. Section 4 presents the main findings, namely that individuals expect a significantly smaller return variance and invest more in original. Evidence in favor of the distracted attention mechanism is provided. Section 5 concludes. 


\section{Theoretical framework}

We adapt a model similar to Ko and Huang (2007); Peress (2010) and Alti and Tetlock (2014). In contrast to these studies, we focus on investor decision-making only. That is, we propose a three-period model in a one-sided market setting. Since we are interested in the role of visual frames, we concentrate on the updating process of integrating new information. We further depart from the literature by integrating the perception of information in this information search model. Therefore, we include two behavioral assumptions on reinforced familiarity and attention. The established model gives our research question analytical structure and allows us to derive concise hypotheses for our experiment.

\subsection{Setup}

In line with the literature, an investor faces a portfolio choice between a risky and a safe asset. Before making her decision, the investor can search for information about the risky asset. In our experiment, this would correspond to reading a disclosure document. Given the outcome of the information search, the investor updates her belief about the risky asset. This translates into three time periods in figure 1 (as in Peress, 2010).

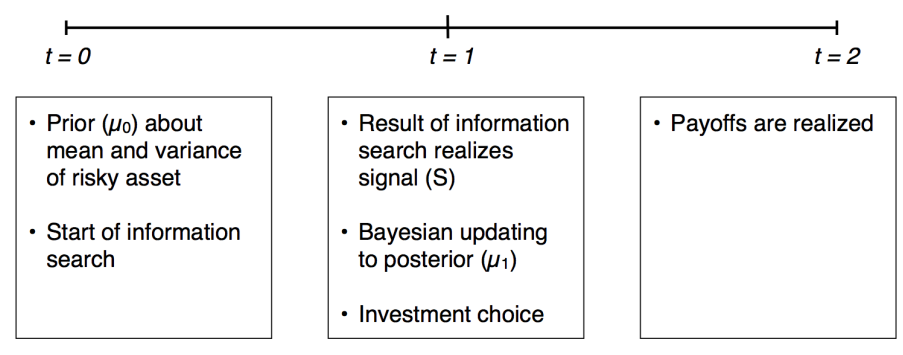

Figure 1: Timing of actions.

In $t=0$, the investor has a subjective prior belief $\mu_{0} \sim N(P, 1 / p)$ about the rate of return of the risky asset, where $P$ defines the subjective prior expected return of the risky asset and $p$ defines the precision of her prior (the inverse of the variance). Information search starts in $t=0$. In $t=1$, the result of her search is realized as a signal. This corresponds to the investor's evaluation of the product based on the information obtained from reading the disclosure document. The signal $S$ is normally distributed around the actual rate of return of the risky asset $\pi$ with $S \sim N(\pi, 1 / s)$, where $s$ defines the precision of the signal. In $t=1$, the investor combines the information of her signal and her prior to form her posterior belief $\mu_{1} \sim N\left(\tilde{\pi}, \sigma^{2}\right)$ about the rate of return of the risky asset in $t=2$. Given this posterior, the investor chooses the optimal portfolio, i.e., the share $x$ of money that she invests in the risky asset. In $t=2$, uncertainty is resolved and payoffs are realized. 


\subsection{Optimal portfolio choice}

In line with Ko and Huang (2007) and Peress (2010), we assume that the investor has CARA utility over final wealth $U[W]=-e^{-\rho W}$ with risk aversion parameter $\rho>0$. That is, we focus on risk aversion. In $t=1$, the investor maximizes expected utility. Since the posterior $\left(\mu_{1}\right)$ is assumed to be normally distributed, final wealth is also normally distributed. Due to these assumptions, we obtain the following mean-variance objective function:

$$
\max _{x} E U\left(W \mid \mu_{1}\right)=E[W]-\frac{\rho}{2} \operatorname{Var}[W] .
$$

Final wealth $(W)$ consists of the payoff from investment in the risky asset and the payoff from investment in the safe asset:

$$
W=x W_{0} \pi+(1-x) W_{0}
$$

where $W_{0}>0$ is the initial wealth in $t=0, x$ is the share invested in the risky asset, $\pi$ is the actual rate of return of the risky asset, and $1-x$ is the share invested in the safe asset. We assume that the safe asset pays no interest. Substituting (2) in (1) leads to

$$
x W_{0} \tilde{\pi}+(1-x) W_{0}-\frac{\rho}{2} \sigma^{2} x^{2} W_{0}^{2},
$$

where $\tilde{\pi}=E[\pi]$ and $\sigma^{2}$ is the variance of the posterior. We assume no short selling ( $x \in$ $[0,1])$. Then, the optimal investment amount in the risky asset $X^{*}=x W_{0}^{*}$ is given by

$$
X^{*}\left(\rho, \tilde{\pi}, \sigma^{2}\right)= \begin{cases}0 & \tilde{\pi} \leq 1 \\ \min \left\{W_{0}, \frac{\tilde{\pi}-1}{\rho \sigma^{2}}\right\} & \text { else. }\end{cases}
$$

As we see, the investor does not invest if the expected rate of return is below one. The optimal amount invested in the risky asset is increasing in the posterior belief (bounded by initial wealth) and decreasing in the risk aversion parameter and the variance.

\subsection{Information signal}

Information search realizes a signal $S \geq 0$ in $t=1$. This signal takes the following form (compare Peress, 2010):

$$
S=\pi+\epsilon \text { with } \epsilon \sim N(0,1 / s)
$$

where $\pi$ is the actual rate of return in $t=2$. The error term $\epsilon$ reflects that the signal is not perfect. For mathematical tractability, the error is assumed to be normally distributed. 
Its variance depends on the precision of the signal $s$. It follows that the signal is normally distributed with $S \sim N(\pi, 1 / s)$.

According to Bayes' Rule for normally distributed variables, combining the prior $\mu_{0}$ with the signal $S$ results in the posterior $\mu_{1} \sim N\left(\tilde{\pi}, \sigma^{2}\right)$ with the following mean and variance:

$$
\begin{gathered}
\tilde{\pi}=E\left[\pi \mid S, \mu_{0}\right]=\frac{p \cdot P+s \cdot S}{p+s}, \\
\sigma^{2}=\operatorname{Var}\left[\pi \mid S, \mu_{0}\right]=\frac{1}{p+s} .
\end{gathered}
$$

The signal enters the posterior in two ways. First, a higher signal leads to a higher expected rate of return. Second, a higher precision of the signal increases the weight of the signal in determining the posterior expected rate of return and also decreases the posterior variance.

\subsection{Behavioral assumptions}

In our experiment, we investigate how different visual frames influence investment choices. We compare a standardized visual frame with a visual frame containing visual distractors. Visual distractors can have an impact on choices. First, from the psychology literature we know that visual distractors influence choices if the working memory load is high (de Fockert et al., 2001; Lavie et al., 2004). Visual distractors automatically draw attention. Shifting attention voluntarily from these features to relevant information costs effort (Itti and Koch, 2001). We call this effect "distracted attention". Second, we know from the behavioral finance literature that investors subject to familiarity bias expect a higher expected rate of return for firms that they are familiar with (Huberman, 2001). We also know from the literature on visual salience that individuals are attracted by graphical representations in financial decisions (de Goeij et al., 2014). Then, visual distractors related to a firm (e.g., a logo) are assumed to trigger familiarity bias more than if one reads firm names, due to visual salience (Enax et al. 2015). We call this second mechanism "reinforced familiarity".

We include these findings by explicitly modelling distracted attention and reinforced familiarity as parameters in the updating process (equations (6) and (7)). Biases are modeled to impact choices through updated beliefs (see also Alti and Tetlock, 2014). In the model, beliefs are influenced by the signal. This signal and its precision follow from information search. We assume that the perception of the search result, i.e., the signal, is influenced by distracted attention and reinforced familiarity 1 . Investors are assumed not to be aware of the impact of these factors. That is, they cannot deliberately influence perception, nor can

\footnotetext{
${ }^{1}$ In Peress (2010) the precision of the signal is an endogenous choice variable. We take the signal precision as given. More precisely, we assume that the treatment variation only changes the perception of the signal.
} 
they take the impact of the factors into account during the decision.

Distinct from previous works, we model distracted attention as overweighting the precision of the signal $(s)$. Investors reading information have a high working memory load which makes them prone to visual distractors (Lavie et al., 2004). We claim that by being distracted, investors gather less information. In particular, relevant information such as disclaimers are less likely to be read. For example, KIDs contain a disclaimer stating that the risk indicator is only based on past development and does not necessarily extrapolate to the future. Not reading this information leads to overweighting the information content of the risk indicator. This implies that the precision of the signal is overestimated. In our model, this is reflected by the weighting parameter $\psi$ of the signal precision $s$. If $\psi>1$, then the precision is overweighted.

Reinforced familiarity is modelled as biasing the signal $S$. Investors link their prior knowledge about the firm to their evaluation of the mutual fund. For example, viewing information of the firm triggers a positive perception of the particular product. Viewing a logo triggers this perception more strongly than reading only the name of the firm, i.e., it reinforces the familiarity bias. We assume that reinforced familiarity leads investors to expect the product to have a higher return. Investors are not aware of this overestimation. We model this overestimation as the weighting parameter $\theta$ in the signal $S$. If $\theta>1$, then the signal is biased upwards. Then, the signal with reinforced familiarity $S_{r}$ takes the following form:

$$
S_{r}=\theta \pi+\epsilon \text { with } \epsilon \sim N(0,1 / s),
$$

where the rate of return $\pi$ is pre-multiplied by reinforced familiarity parameter $\theta$. If $\theta=1$ the signal is unbiased and the formula is identical to (5). Applying Bayes' rule and including the distracted attention parameter in equations (6) and (7), we arrive at the following mean and variance of the posterior:

$$
\begin{gathered}
\tilde{\pi}=E\left[\pi \mid S, \mu_{0}\right]=\frac{p \cdot P+\psi s \cdot S_{r}}{p+\psi s}, \\
\sigma^{2}=\operatorname{Var}\left[\pi \mid S, \mu_{0}\right]=\frac{1}{p+\psi s} .
\end{gathered}
$$

Reinforced familiarity distorts the signal and distracted attention leads investors to overestimate the precision of the signal. Investors put higher weight on the signal and its precision than in the unbiased posterior in equations (6) and (7). We can see that the posterior expected value is increasing in $\theta$ through the signal $S_{r}$. The posterior variance is decreasing in $\psi$. For the posterior expected value, we can also see that both parameters reinforce each 
other. That is, the influence of reinforced familiarity on the investment decision is higher when the signal is over-weighted. Note that the model reduces to the standard case for $\theta=1$ and $\psi=1$. Beliefs are predicted to impact choices. That is, a higher weight on the signal increases the weight the distorted signal has on the investment decision.

\subsection{Experimental hypotheses}

Our model predicts investment behavior through updated beliefs. Reinforced familiarity and distracted attention parameters differ between familiar $(f)$ and unfamiliar $(u)$ firms and between the original $(O)$ and neutral $(N)$ treatment. Therefore, expectations and choices are predicted to differ between treatments.

Concerning the reinforced familiarity parameter, we assume that $\theta_{f}>1$ for familiar firms and $\theta_{u}=1$ for unfamiliar firms. That means familiarity bias only impacts expectations if firms are known. Familiarity bias is reinforced if firm-specific visual distractors are present $\left(\theta_{O-f}>\theta_{N-f}\right)$. Then, on average, reinforced familiarity leads to more positive signals over the expected value:

$$
\tilde{\pi}_{O-f}>\tilde{\pi}_{N-f}>\tilde{\pi}_{N-u}=\tilde{\pi}_{O-u}
$$

Larger expected values result in higher investments for familiar firms.

Hypothesis 1. If reinforced familiarity is the driving factor, we observe a larger treatment difference in expected values and investments for familiar firms compared to unfamiliar firms.

For the distracted attention parameter, we assume $\psi=1$ in the neutral treatment and $\psi>1$ in the original treatment. That is, the presence of visual distractors leads to attention distraction in the original treatment. The precision of the signal is overestimated $(\psi s>$ $s)$. Thus, the expected variance of the posterior is predicted to be smaller in the original treatment:

$$
\sigma_{O}^{2}<\sigma_{N}^{2}
$$

A lower variance induces higher investments.

Hypothesis 2. If distracted attention is the driving factor, we observe a lower expected variance and higher investments in the original compared to the neutral treatment. 
Distracted attention and reinforced familiarity interact with each other as can be seen from (9). Distracted attention leads to an overestimation of the signal precision and fosters overweighting of the signal. Therefore, the effect of reinforced familiarity is increased. If, on average, the signal is more positive, this leads to a higher expected value $(\tilde{\pi})$ for familiar firms. This impact is even larger if visual distractors are present (e.g., in original). Given the posterior belief predictions from equations (9) and (10) and the optimal share of the risky asset in equation (4), we arrive at the following predictions for investment behavior:

$$
X_{O-f}^{*}>X_{N-f}^{*}>X_{N-u}^{*}, \quad X_{O-f}^{*}>X_{O-u}^{*}>X_{N-u}^{*}
$$

The predicted invested amount $\left(X^{*}=x W_{0}^{*}\right)$ is higher in the original treatment than in the neutral treatment. Within each treatment, the invested amount is predicted to be larger for familiar compared to unfamiliar firms.

Hypothesis 3. If both, reinforced familiarity and distracted attention are present, we observe

(i) lower expected variance in original than in neutral,

(ii) larger treatment difference in expected value for familiar firms,

(iii) higher investments for firms in original compared to neutral and

(iv) larger treatment differences in investment for familiar firms. 


\section{Experimental design}

We investigate the impact of changing the visual frame on expectations and investment behavior. Our hypotheses are tested in a controlled laboratory experiment resembling properties of financial decision-making in the field. In our setting, subjects face an investment problem based on real-life mutual fund investor information documents.

We employ a between-subjects design. Participants are randomly assigned either to the original or the neutral treatment group. The groups receive different documents containing the same information. Subjects in the original treatment group are given the real investor document of a mutual fund. Precisely, we employ KIDs under EU regulation UCITS IV Directive 2009/65/EC. That is, visual distractors are present in original. Participants in the neutral treatment group get the same information. The only variation is the visual frame of the documents. In neutral, the visual frame is standardized (see appendix C). That is, visual distractors are removed. We regard banners, logos, and colors to be visual distractors. Information in the documents is constant across both treatment groups. Also, instructions are equivalent for both groups (see appendix E).

Figure 2 presents the experimental setup with two parts: expectation elicitation and investment choice. First, individuals state their beliefs about the funds' future return. Second, they face an investment decision. Both are repeated in four stages. In each stage, a different fund is considered. We vary the familiarity of the firms across stages. The order of the stages is randomized individually to control for order effects.

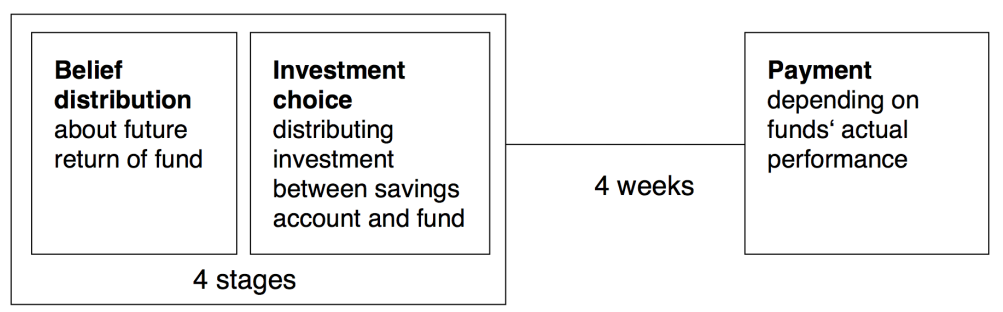

Figure 2: Experimental setup.

Information documents are distributed before each stage. After completion of each stage, documents are recollected. Note that we elicit the expected value $(\tilde{\pi})$, the expected variance $\left(\sigma^{2}\right)$, and the investment choice $(X)$ from the subjects.

The fund sample consists of mutual funds investing in bonds (see table 3 in appendix A). Two funds from familiar firms (DekaBank and Allianz Global Investors) and two funds from unfamiliar firms (ACM Bernstein and Pioneer Investments) are included in the sample.2

\footnotetext{
${ }^{2}$ Based on the literature, we select funds according to front-end load, annual expenses, return history,
} 
Participants are incentivized in both tasks. They receive their payment four weeks after the experiment. In order to determine the payment, one stage out of four is chosen randomly for each subject. Then, either the expectation or the investment task is chosen randomly to be payoff relevant for each individual subject. In this way, hedging effects between stating beliefs and choices are avoided (Blanco et al., 2010). Subjects earn points during the experiment which are exchanged at a rate of 1/800 to euros. Participants face no time constraints. We track their "reading time" of the information documents for the complete stage. That is, total reading time includes reading the documents, the expectation, and the investment task. Participants can leave the laboratory after they have finished the tasks. This induces the dilemma we observe in the field, namely that individuals may not want to sacrifice their leisure time to read the documents.

Following the main experiment, participants answer a questionnaire. Questions include a portfolio allocation task between all funds as well as participants' demographic characteristics, income, familiarity with the fund and investment experience as well as possible background factors impacting the decision, debriefing questions, financial literacy and a cognitive reflection test. Thus, we can control for additional explanatory factors. Additionally, we also ask multiple choice questions about the content of the documents in order to get insights into how well the information documents were read. We elicit risk and ambiguity aversion using multiple choice lists following the approach of Gneezy et al. (2015).

\subsection{Part 1: Expectation elicitation}

Expectations are elicited as a subjective belief distribution based on a variation of Harrison et al. (2013b) and Delavande and Rohwedder (2008). A twelve-binned histogram is used. Each interval encompasses a two percentage range. Subjects distribute 100 tokens on intervals according to their expectation about the funds' future return.

The subjective belief distribution is incentivized by a randomized version of the quadratic scoring rule (Harrison et al., 2013a; Hossain and Okui, 2013). Under this scoring rule, participants have an incentive to truthfully report their subjective probability distribution. Participants can either earn a fixed payoff of 20 or 0 euros (Hossain and Okui, 2013). Their payoff depends on their stated belief distribution, a random number and the funds' net return after four weeks.

In order to determine the payoff from the belief task $\left(w_{i}\right)$ for each individual $i$, a random number $r$ is drawn independently from $U[0,1]$. The corresponding belief payoff function is

and the risk indicator (1-7), which we consider to be reasonable for an investment with a 4-week horizon. Additionally, mutual funds containing the term "Euro" in the title as well as funds denominated in euro are selected to control for the impact of home bias (Coval and Moskowitz, 1999). 
described by the following equation:

$$
w_{i}= \begin{cases}20 & \text { if } \quad \sum_{k=1}^{12}\left(b_{k}-\mathbf{1}_{k}\right)^{2} \leq r \\ 0 & \text { else }\end{cases}
$$

where $b_{k}$ represents the stated number of normalized tokens in each bin $k \in(0,1)$. The indicator function $\mathbf{1}_{k}$ equals 1 if the actual net return of the fund lies in bin $k$ and 0 otherwise.

The payoff $w_{i}$ depends on the accuracy of the belief estimate. Accuracy is captured by $a_{i}=\sum_{k=1}^{12}\left(b_{k}-\mathbf{1}_{k}\right)^{2}$. If $a_{i}$ is small, then accuracy with regard to the actual return is high. This score $a_{i}$ determines the chance of getting a high payoff independently of the amount of payment. If the random number $r$ independently drawn from $U[0,1]$ is larger than or equal $a_{i}$, then the participant receives 20 euros and nothing otherwise. At the beginning of the experiment, participants practice this procedure. We employ control questions to make sure that participants understand the incentive scheme.

\subsection{Part 2: Investment decision}

We consider the standard portfolio choice problem in finance (Markowitz, 1952). Individuals choose how much of their endowment they want to invest in a risky fund (Huck et al., 2014). Participants invest by distributing 12000 points (15 euros) between a safe asset with a rate of return of $0.1 \%$ per year and the fund with an ambiguous rate of return. The safe asset is framed as a savings account and its rate of return resembles the interest rate in the market.

\subsection{Procedure}

The experiment was conducted at BonnEconLab on 14 and 15 April 2015. In sum, $N=182$ participants took part in the experiment: $n=87$ in the original and $n=95$ in the neutral treatment. Participants needed between 55 and 140 minutes to complete the session. They earned on average 14,20 euros. The experiment was programmed using the experimental software z-Tree (Fischbacher, 2007). Participants were recruited from the BonnEconLab subject pool (more than 6000 subjects) using hroot (Bock et al., 2014). 


\section{Results}

\subsection{Investment behavior}

We predict differences in investment behavior and in expectations between treatment groups. To start, we look at investment behavior. Our experimental hypotheses claim that individuals invest more in the original treatment than in the neutral treatment condition. We find supporting evidence.

Result 1. Individuals invest on average more into the fund in the original compared to the neutral treatment.

Support. Figure 3 displays investment amounts into the fund by treatment pooled across all four funds. We reject the null hypothesis that investments into funds do not differ between treatments based on the Mann-Whitney $\mathrm{U}$ test (two-sided, $p=0.0509$ ). Directly testing our directional hypothesis indicates that individuals invest significantly more in original (one-sided Mann-Whitney $\mathrm{U}, p=0.0255$ ).

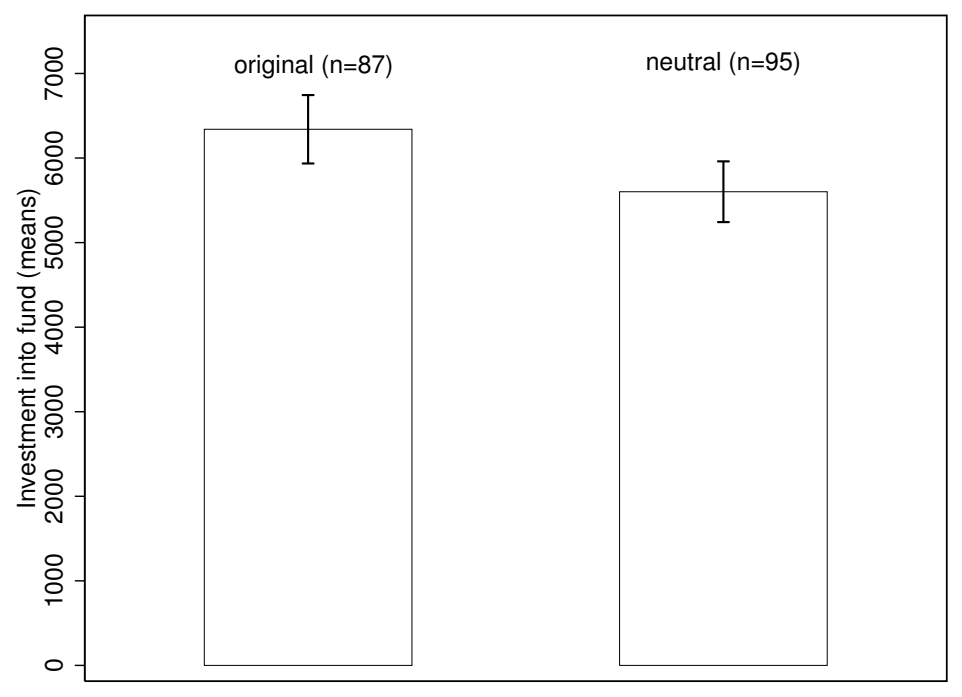

Figure 3: Investments pooled across funds by treatment (error bars: 95\% confidence intervals).

On average, participants invest $14 \%$ more in the fund in the original (6340 points) than in the neutral (5602 points) disclosure treatment. This overall direction holds across funds.

Figure 4 plots investment differences between treatments for each fund. The lower point represents mean investment in the neutral treatment, whereas the upper point plots the mean in the original treatment across individuals. At the individual fund level, investments differ 
in the hypothesized direction, i.e., investments are on average lower in neutral. According to the one-sided Mann-Whitney U test, mean investments (neutral, original) are significantly larger in original for ACM $(4374,5396)(p=0.032)$, Pioneer $(6176,6898)(p=0.076)$ and Allianz GI $(6485,7173)$ ( $p=0.081)$. The treatment difference for DekaBank fund (5372, $5894)$ is not significant $(p=0.196)$.

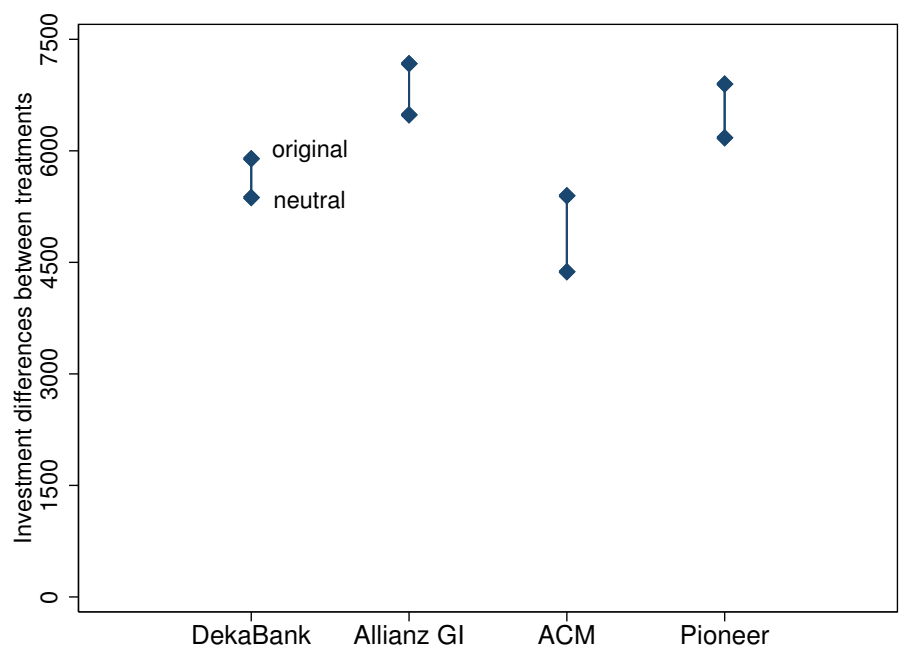

Figure 4: Investment differences between treatments by fund.

DekaBank and Allianz Global Investors are denoted as familiar, ACM Bernstein and Pioneer Investments as unfamiliar firms ${ }^{3}$ Individuals invest on average more in familiar firms (Wilcoxon signed-rank test, $p=0.0038$ ). Figure 4 suggests that familiarity does not play a role for the size of the treatment effect. Hypothesis 1 states that treatment differences are larger for familiar firms due to reinforced familiarity. We do not find evidence supporting this prediction.

In order to reach a deeper understanding of the investment behavior, we look at the pooled distribution of investments. Figure 5 shows kernel density estimates by treatment. The black solid line plots the kernel density estimate of the pooled investments in the original treatment, whereas the red dashed line shows the corresponding kernel estimate of pooled investments in the neutral treatment. Assuming continuous distribution of investment on a metric scale, the two-sample Kolmogorov-Smirnov test for equality of distribution functions indicates that the investment distributions differ significantly $(p=0.012)$.

\footnotetext{
${ }^{3}$ Answers from subjects in the questionnaire are consistent with this classification. Subjects had to rate for each firm how well they know it. Subjects knew the familiar firms better than the unfamiliar firms (Wilcoxon signed-rank test, $p<0.001$ ).
} 
Most participants invest around half of their endowment into the ambiguous fund. This corresponds to a $1 / n$ diversification strategy (Benartzi and Thaler, 2001). Compared to the original kernel estimate, the neutral kernel is narrower in the center and left-shifted. The kernel estimate of investment in the original treatment condition has larger tails on the right of the distribution. We find more positive extreme fund investments in the original treatment.

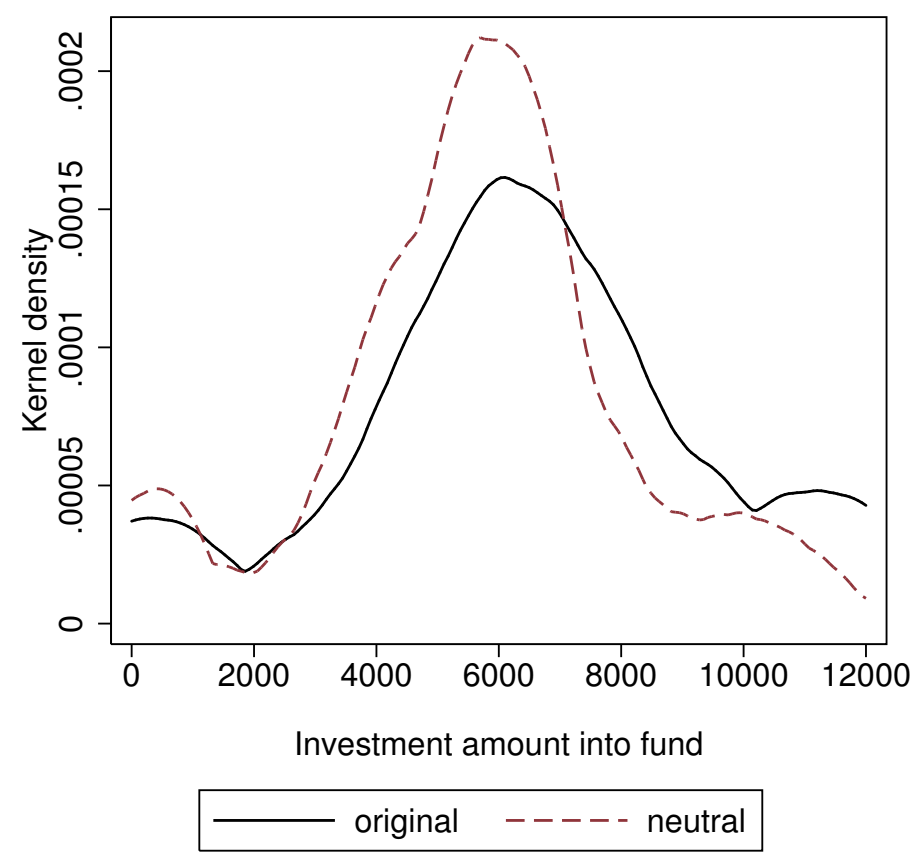

Figure 5: Kernel density estimates of investment by treatment. Estimates based on the Epanechnikov kernel function and Sheather-Jones plugin bandwidth selection criterion.

Determinants of the investment choice are investigated in a multiple linear regression. Table 1 presents the results. The dependent variable is the individual investment amount into the mutual fund for each of the four rounds. In this way, we obtain a panel data structure with $182 \times 4=728$ observations. The main treatment effect is estimated by including a dummy variable that indicates 0 if investments are made in the original treatment condition and 1 if they are made in the neutral treatment. We find a significant main effect of our treatment on investment under various specifications controlling for a large number of explanatory factors. This result is in line with our descriptive findings. 
Table 1: Treatment Effect: Random Effects Estimation Results for Investment.

\begin{tabular}{|c|c|c|c|c|c|}
\hline & (1) & (2) & $(3)$ & $(4)$ & $(5)$ \\
\hline Treatment (neutral) & $\begin{array}{l}-738.7^{*} \\
(420.7)\end{array}$ & $\begin{array}{l}-738.7^{*} \\
(420.7)\end{array}$ & $\begin{array}{c}-872.2^{*} \\
(467.1)\end{array}$ & $\begin{array}{c}-775.6^{*} \\
(461.3)\end{array}$ & $\begin{array}{c}-1086.1^{* *} \\
(478.1)\end{array}$ \\
\hline Familiar & & $\begin{array}{c}525.7^{* * *} \\
(202.8)\end{array}$ & $\begin{array}{c}386.3 \\
(293.5)\end{array}$ & $\begin{array}{c}335.6 \\
(261.0)\end{array}$ & $\begin{array}{c}133.3 \\
(358.2)\end{array}$ \\
\hline Treatment $X$ familiar & & & $\begin{array}{c}267.1 \\
(406.2)\end{array}$ & $\begin{array}{c}215.9 \\
(361.5)\end{array}$ & $\begin{array}{c}286.1 \\
(363.3)\end{array}$ \\
\hline Expected value & & & & $\begin{array}{c}475.1^{* * *} \\
(39.69)\end{array}$ & $\begin{array}{c}469.9^{* * *} \\
(40.07)\end{array}$ \\
\hline Expected variance & & & & $\begin{array}{l}-16.87 \\
(18.98)\end{array}$ & $\begin{array}{l}-20.09 \\
(19.36)\end{array}$ \\
\hline Risk aversion & & & & $\begin{array}{c}145.3 \\
(889.1)\end{array}$ & $\begin{array}{l}-70.31 \\
(942.6)\end{array}$ \\
\hline Ambiguity aversion & & & & $\begin{array}{c}-1645.0 \\
(1127.3)\end{array}$ & $\begin{array}{c}-1586.0 \\
(1193.4)\end{array}$ \\
\hline Priors & & & & & Yes \\
\hline Rounds & & & & & Yes \\
\hline Set of controls ${ }^{+}$ & & & & & Yes \\
\hline Constant & $\begin{array}{c}6340.3^{* * *} \\
(303.9)\end{array}$ & $\begin{array}{c}6077.4^{* * *} \\
(320.4)\end{array}$ & $\begin{array}{c}6147.2^{* * *} \\
(337.5)\end{array}$ & $\begin{array}{c}-41508.8^{* * *} \\
(4145.2)\end{array}$ & $\begin{array}{c}-39633.1^{* * *} \\
\quad(5928.3)\end{array}$ \\
\hline Observations & 728 & 728 & 728 & 728 & 728 \\
\hline $\operatorname{Adj} R^{2}$ & 0.0099 & 0.0149 & 0.0152 & 0.1010 & 0.210 \\
\hline
\end{tabular}

+ Set of controls includes demographic characteristics, attitude towards financial markets, firm knowledge, (prospective) fund ownership, reading time, financial literacy, cognitive reflection, time inconsistency, impression of documents, and macroeconomic environment.

Random effects (GLS) estimation. Standard errors in parentheses.

Dependent variable: investment amount (points) into mutual fund.

Familiar is a dummy which takes the value 1 for familiar firms and 0 otherwise.

Significance level: ${ }^{*} p<0.10,{ }^{* *} p<0.05,{ }^{* * *} p<0.01$.

All explanatory variables have the expected sign. The neutral treatment is significantly negatively associated with investment into the fund. Being in the neutral group, participants invest significantly less in the fund. Expected value is positively significantly related with investing into the fund. The impact of variance is not significant. In line with the literature, risk and ambiguity aversion could also explain investment behavior. However, we do not find a significant influence of risk or ambiguity $\left.\right|^{4}$ The results are in line with our hypotheses concerning the overall treatment effect on investments. The main treatment effect stays

\footnotetext{
${ }^{4}$ We elicit the parameters with multiple choice lists and the method used by Gneezy et al. (2015). Since we elicited the parameters after the main experiment, this might introduce background risk leading to increased risk-aversion, confounding our measurement results (see, e.g., Harrison et al., 2007).
} 
significant after including further explanatory variables into the model. The full model (5) includes in total 32 explanatory factors that could possibly also influence investment behavior. Results on individual investments are robust and consistent.

Result 2. Familiarity does not impact the size of the treatment effect on investments.

Support. Estimation results in table 1 suggest that there is no evidence for a significant interaction effect between familiarity and treatment. The treatment difference in investments is not significantly higher for familiar firms. This is in line with descriptive finding from figure 4 that the largest investment treatment difference is found for an unfamiliar fund.

\subsection{Expectations}

Subjective expectations are predicted to be a major determinant of investment choices by our model. We predict that expected return values are larger conditional on familiarity (hypotheses 1 and 3) and that posterior return variances will be smaller (hypothesis 2) in the original treatment compared to the neutral treatment. Indeed, we find evidence that expected return variance is smaller in original.

Result 3. There is an average treatment effect on expected return variance. Individuals expect a smaller return variance in the original treatment.

Support. Table 2 presents participants' expectations from the prediction task. Mean expected return variance across funds is found to be significantly different in the neutral compared to the original treatment (two-sided, $p=0.036$ ).

Table 2: Subjective expectations: expected value and variance.

\begin{tabular}{lccccccc}
\hline \hline Treatment & Obs. & \multirow{2}{*}{ Mean } & Mean & Probability & \multicolumn{2}{c}{ P-value Mann-Whitney U } \\
\cline { 6 - 8 } & & EV & Variance & Mass (+) & EV & Variance & Mass (+) \\
\hline Original & 87 & 102.12 & 3.75 & 78.16 & 0.576 & 0.036 & 0.082 \\
Neutral & 95 & 101.97 & 4.91 & 74.89 & & & \\
\hline \hline
\end{tabular}

Expected value and variance are derived from the subjective belief distribution about the return of the funds. Average values are pooled across funds.

Positive probability mass $(+)$ is defined as the probability mass (0 to 100)

in intervals with a positive rate of return.

On average, individuals expect returns to have a smaller variance in original. Then, we find evidence supporting hypothesis 2. According to hypothesis 3, the expected value should be 
higher for familiar firms and even higher when visual distractors are present. We do not find evidence for the hypothesis on expected value $5^{5}$

Result 4. There is no average treatment effect on expected values. Also, familiarity does not play a role for the expected value.

Support. Difference in mean expected values in table 2 is not statistically significant (twosided, $p=0.576$ ). We use a random effects regression of the expected value on the treatment, familiarity, and the interaction term between treatment and familiarity. The expected value is lower in the neutral treatment (coefficient $-0.189, p=0.567$ ), higher for familiar firms (coefficient 0.097, $p=0.714$ ), and even higher for familiar firms in the neutral treatment (coefficient interaction term $0.079, p=0.831$ ). However, none of these factors are significant.

Subjects in original put on average significantly more probability mass into the positive domain of the expectation distribution. That is, individuals expect on average more positive net returns in original. In sum, we find empirical evidence in expectation data supporting our model predictions based on expected variance, but not based on average expected value.

\subsection{Mechanism}

Based on the analysis of choice and expectation data, we reject hypotheses 1 and 3 . We do not find evidence of the treatment effect being conditional on familiarity. Familiarity provides only a level effect on investment. There is no interaction effect with the treatment.

We find evidence in line with hypothesis 2 . Therefore, distracted attention is proposed to be the main mechanism behind our results. Now, we provide additional evidence based on reading times and comprehension questions supporting this hypothesis.

Result 5. Individuals take more time reading the neutral documents and gather more correct information from reading it.

Support. Figure 6 presents reading times by round for each treatment. Average reading times over all rounds are longer in the neutral treatment (6.6 minutes) compared to the original treatment (5.7 minutes; Mann-Whitney $\mathrm{U}, p=0.0129$ ). Employing evidence from post-experimental questions, we find that participants in the neutral treatment group gather on average significantly more correct information compared to the original treatment group.

\footnotetext{
${ }^{5}$ We calculate the expected value as a joint product of the midpoints of the intervals and its corresponding probability mass. We thereby assume that the open outer intervals end at 89 and 111, respectively.

In line with the literature, as a robustness check, the expected value is also calculated using cubic spline interpolation with Hyman filter (Bellemare et al. 2012 , see table 5 in appendix A).
} 


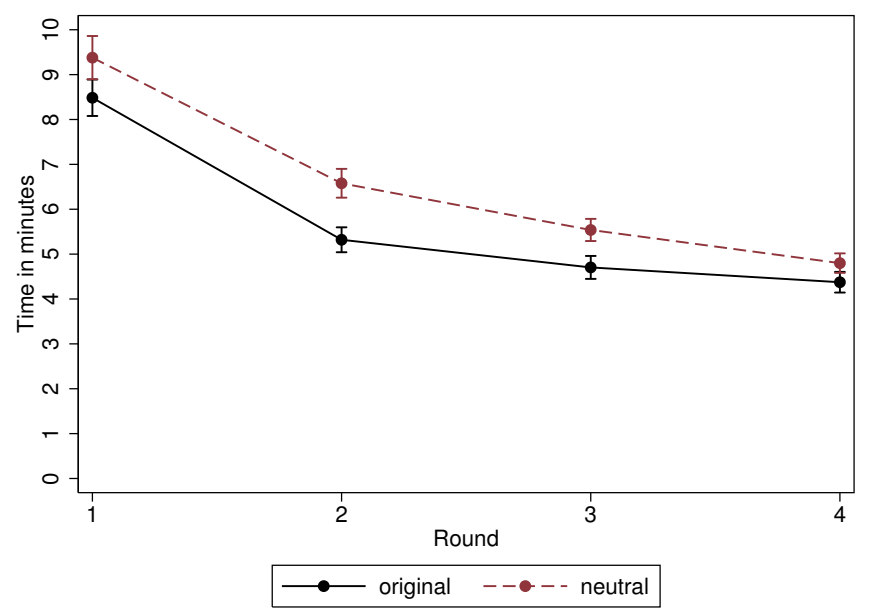

Figure 6: Reading time for each treatment by round (error bars: 95\% confidence intervals).

The red dashed line corresponds to the neutral treatment and the solid black line corresponds to the original treatment. Difference between treatments persists across rounds. Average reading time decreases sharply after the first round and converges in the following rounds.

We asked participants multiple choice questions (one out of four) about the content and understanding of the documents (after making sure that they were not keeping any documents on their desks). In particular, we find that participants recognize the KIDs to be legal documents more often in the neutral treatment (77\%) compared to the original treatment (64\%; Mann-Whitney $\mathrm{U}, p=0.065)$. The risk indicator in the documents is based on historical data and may be subject to substantial change in the future. This fact is more often correctly understood in neutral (65\%) compared to original (53\%; Mann-Whitney $\mathrm{U}, p=0.090)$. Further, the nature of past return data is also better understood in the neutral condition (Mann-Whitney $\mathrm{U}, p=0.066$ ). Past returns are provided annually and are not predictive for future earnings. In sum, we find that individuals gather more correct information in the neutral treatment.

This provides additional evidence in favor of the distracted attention hypothesis 2 . Interestingly, subjects perceive the documents equally informative in original (4.05 on a 6-point likert scale) as in neutral (4.15, Mann-Whitney $\mathrm{U}, p=0.618)$ suggesting that they are not aware of being distracted. Multiple choice questions were asked after subjects read four different information documents. Each of these documents contained all the relevant information to answer all questions correctly. Then, the treatment effect is found to be persistent and does not vanish due to learning. In combination with the decreasing reading times, this suggests that subjects focus only on specific parts of the original documents and keep this pattern constant across trials. That is, we find that subjects do not improve by experience. 


\section{Discussion and conclusion}

In this paper, we study whether changing the visual frame of disclosure documents influences expectations and investment behavior. The visual frame is varied by removing visual distractors. We find that subjects in the original treatment invest more in the mutual funds. Individuals expect returns of the funds to be less risky in the original treatment (visual distractors being present) compared to the neutral treatment.

Treatment differences cannot be explained by reinforced familiarity, but by distracted attention. Reading times and questionnaire data provide additional evidence for the distracted attention hypothesis. Participants take more time to read documents and comprehend them better if confronted with a standardized visual frame without visual distractors.

The results provide limited empirical support for our theoretical framework. We do find higher investments in the original treatment. However, familiarity does not affect this treatment difference. On the other hand, we find evidence for distracted attention and a lower variance in the estimates of the individuals, which is in line with our model. Further, individuals in the neutral treatment put on average less probability mass in the positive domain of the expectation distribution. This can be attributed to the distracted attention hypothesis. Subjects in neutral are more likely to read information, which makes them more cautious in their decision. Being more cautious, negative outcomes are more often considered in neutral, leading to a larger expected return variance in neutral.

An alternative explanation for our results could be perceived trustworthiness of the documents. That is, the documents featuring firm logo and layout in the original treatment could, in principle, signal more trustworthiness compared to the documents in the neutral treatment. Participants would invest because they have the impression that the original document is more reliable than the neutral one. However, we find from questionnaire data that impressions of the documents do not differ between treatments. Both treatment documents are found to be equally reliable (Mann-Whitney $\mathrm{U}, p=0.403$ ) and credible (Mann-Whitney $\mathrm{U}, p=0.670)$. Moreover, brand perception as a decision factor does not differ significantly between treatments (Mann-Whitney $\mathrm{U}, p=0.144$ ).

From the actual development of the funds (see table 4 in appendix A), we can see that actual returns are volatile and lie below participants' expectations. In our four-week investment horizon, net returns decrease up to $-5.53 \%$. Participants are paid according to net

returns (including fees and expenses) in expectation and choice tasks. Net return is negative for all funds. That is, in our experiment, and given the specific development of the funds, investors would have ex post optimally invested their whole endowment in the safe asset. 
KID documents were introduced in order to help retail investors make better-informed decisions. Our results show that in reaching this goal the visual frame is not innocent. Indeed, we find evidence that limited attention negatively affects efficacy of mandatory disclosure policies as suggested by Loewenstein et al. (2014). Investors are distracted, which leads them to gather less correct information. Importantly, experience does not improve the situation. On the contrary, individuals seem to miss the same important information over and over again, leading to a constant overvaluation of the fund. If policy makers aim at information disclosures which inform investors best, then they have to go beyond information. Removing visual distractors, by standardizing the visual frame, can help to improve disclosure efficacy. 


\section{References}

Aaker, D. A. (2009). Managing Brand Equity. Simon and Schuster.

Alti, A. and Tetrock, P. C. (2014). Biased Beliefs, Asset Prices, and Investment: A Structural Approach. The Journal of Finance, 69 (1), 325-361.

Baker, W., Hutchinson, J., Moore, D. and Nedungadi, P. (1986). Brand Familiarity and Advertising: Effects on the Evoked Set and Brand Preference. Advances in Consumer Research, 13, 637-642.

Barber, B. M., Odean, T. and Zheng, L. (2006). Out of sight, out of mind: The effects of expenses on mutual fund flows. Journal of Business, 78 (6), 2095-2120.

Bellemare, C., Bissonnette, L. and Kröger, S. (2012). Flexible Approximation of Subjective Expectations using Probability Questions. Journal of Business 85 Economic Statistics, 30 (1), 125-131.

Benartzi, S. and Thaler, R. H. (2001). Naive Diversification Strategies in Defined Contribution Saving Plans. American Economic Review, 91 (1), 79-98.

Bertrand, M., Karlan, D., Mullainathan, S., Shafir, E. and Zinman, J. (2010). What's Advertising Content Worth? Evidence from a Consumer Credit Marketing Field Experiment. The Quarterly Journal of Economics, 125 (1), 263-306.

— and Morse, A. (2011). Information Disclosure, Cognitive Biases, and Payday Borrowing. The Journal of Finance, 66 (6), 1865-1893.

Beshears, J., Choi, J. J., Laibson, D. and Madrian, B. C. (2011). How Does Simplified Disclosure Affect Individuals Mutual Fund Choices? In Explorations in the Economics of Aging, University of Chicago Press, pp. 75-96.

Beshears, J. L., Choi, J. J., Laibson, D., Madrian, B. C. and Milkman, K. L. (2014). The Effect of Providing Peer Information on Retirement Savings Decisions. The Journal of Finance, forthcoming.

Bhargava, S. and Loewenstein, G. (2015). Behavioral Economics and Public Policy 102: Beyond Nudging. American Economic Review, 105 (5), 396-401.

Blanco, M., Engelmann, D., Koch, A. K. and Normann, H.-T. (2010). Belief Elicitation in Experiments: Is there a Hedging Problem? Experimental Economics, 13 (4), $412-438$. 
Bock, O., Baetge, I. and Nicklisch, A. (2014). hroot: Hamburg registration and organization online tool. European Economic Review, 71, 117-120.

Campbell, J. Y., Jackson, H. E., Madrian, B. C. and Tufano, P. (2011). Consumer Financial Protection. Journal of Economic Perspectives, 25 (1), 91-114.

Chater, N., Huck, S. and Inderst, R. (2010). Consumer Decision-Making in Retail Investment Services: A Behavioural Economics Perspective. Final Report prepared for SANCO/EC. http://ec.europa.eu/consumers/archive/strategy/ consumer_behaviour_en.htm.

Choi, J. J., Laibson, D. and Madrian, B. C. (2010). Why Does the Law of One Price Fail? An Experiment on Index Mutual Funds. Review of Financial Studies, 23 (4), 14051432.

Coval, J. D. and Moskowitz, T. J. (1999). Home Bias at Home: Local Equity Preference in Domestic Portfolios. The Journal of Finance, 54 (6), 2045-2073.

Cronqvist, H. (2006). Advertising and Portfolio Choice. Mimeo.

de Fockert, J. W., Rees, G., Frith, C. D. and Lavie, N. (2001). The Role of Working Memory in Visual Selective Attention. Science, 291 (5509), 1803-1806.

de Goeis, P., Hogendoorn, T. and Campenhout, G. V. (2014). Pictures are Worth a Thousand Words: Graphical Information and Investment Decision Making. Mimeo.

Delavande, A. and Rohwedder, S. (2008). Eliciting Subjective Probabilities in Internet Surveys. Public Opinion Quarterly, 72 (5), 866-891.

Enax, L., Krapp, V., Piehl, A. and Weber, B. (2015). Effects of Social Sustainability Signals on Neural Valuation Signals and Taste-experience of Food Products. Frontiers in Behavioral Neuroscience, 9, 247.

European Parliament and Council of European Union (2009). UCITS Directive 2009/65/EC of 13 July 2009. http://eur-lex. europa.eu/legal-content/EN/TXT/ ?uri=celex: $32009 \mathrm{~L} 0065$.

FischbacheR, U. (2007). z-Tree: Zurich Toolbox for Ready-made Economic Experiments. Experimental Economics, 10 (2), 171-178.

Gneezy, U., Imas, A. and List, J. (2015). Estimating Individual Ambiguity Aversion: A Simple Approach. Mimeo. 
Harrison, G. W., List, J. A. and Towe, C. (2007). Naturally Occurring Preferences and Exogenous Laboratory Experiments: A Case Study of Risk Aversion. Econometrica, $75(2), 433-458$.

-, Martínez-Correa, J. and Swarthout, J. T. (2013a). Inducing Risk Neutral Preferences with Binary Lotteries: A Reconsideration. Journal of Economic Behavior $\mathcal{E}$ Organization, 94, 145-159.

—, -, Swarthout, J. T. and Ulm, E. R. (2013b). Scoring Rules for Subjective Probability Distributions.

Hendricks, D., Patel, J. and Zeckhauser, R. (1993). Hot Hands in Mutual Funds: Short-run Persistence of Relative Performance, 1974-1988. The Journal of Finance, 48 (1), 93-130.

Hoeffler, S. and Keller, K. L. (2003). The marketing advantages of strong brands. The Journal of Brand Management, 10 (6), 421-445.

Hossain, T. and Okui, R. (2013). The Binarized Scoring Rule. The Review of Economic Studies, 80 (3), 984-1001.

Huberman, G. (2001). Familiarity breeds Investment. Review of Financial Studies, 14 (3), 659-680.

Huck, S., Schmidt, T. and Weizsëcker, G. (2014). The Standard Portfolio Choice Problem in Germany. Mimeo.

IFF Research and Yougov (2009). UCITS Disclosure Testing Research Report Prepared for European Commission. ec.europa.eu/finance/investment/docs/other_ docs/research_report_en.pdf

Itтı, L. and Koch, C. (2001). Computational Modelling of Visual Attention. Nature Reviews Neuroscience, 2 (3), 194-203.

Jain, P. C. and Wu, J. S. (2000). Truth in Mutual Fund Advertising: Evidence on Future Performance and Fund Flows. The Journal of Finance, 55 (2), 937-958.

JarvenpaA, S. L. (1989). The Effect of Task Demands and Graphical Format on Information Processing Strategies. Management Science, 35 (3), 285-303.

- (1990). Graphic Displays in Decision Making - the Visual Salience Effect. Journal of Behavioral Decision Making, 3 (4), 247-262. 
Kaufmann, C. and Weber, M. (2013). Sometimes Less is More-The Influence of Information Aggregation on Investment decisions. Journal of Economic Behavior 83 Organization, 95, 20-33.

—, - and Haisley, E. (2013). The Role of Experience Sampling and Graphical Displays on One's Investment Risk Appetite. Management Science, 59 (2), 323-340.

Ko, K. J. and Huang, Z. J. (2007). Arrogance can be a Virtue: Overconfidence, Information Acquisition, and Market Efficiency. Journal of Financial Economics, 84 (2), $529-560$.

Koenler, J. J. and Mercer, M. (2009). Selection Neglect in Mutual Fund Advertisements. Management Science, 55 (7), 1107-1121.

Kozup, J., Howlett, E. and Pagano, M. (2008). The Effects of Summary Information on Consumer Perceptions of Mutual Fund Characteristics. Journal of Consumer Affairs, $42(1), 37-59$.

Lavie, N., Hirst, A., De Fockert, J. W. and Viding, E. (2004). Load Theory of Selective Attention and Cognitive Control. Journal of Experimental Psychology: General, 133 (3), 339-354.

Lee, T. D., Yun, T. and Haley, E. (2012). The Interplay between Advertising Disclosures and Financial Knowledge in Mutual Fund Investment Decisions. Journal of Consumer Affairs, 46 (2), 260-287.

Loewenstein, G., Sunstein, C. R. and Golman, R. (2014). Disclosure: Psychology Changes Everything. Annual Review of Economics, 6 (1), 391-419.

Markowitz, H. (1952). Portfolio Selection. The Journal of Finance, 7 (1), 77-91.

Park, C. W., Eisingerich, A. B., Pol, G. and Park, J. W. (2013). The role of brand logos in firm performance. Journal of Business Research, 66 (2), 180-187.

Peress, J. (2010). The Tradeoff between Risk Sharing and Information Production in Financial Markets. Journal of Economic Theory, 145 (1), 124-155.

Pontari, B. A., Stanaland, A. J. S. and Smythe, T. (2009). Regulating Information Disclosure in Mutual Fund Advertising in the United States: Will Consumers Utilize Cost Information? Journal of Consumer Policy, 32 (4), 333-351. 
Sapp, T. and Tiwari, A. (2004). Does Stock Return Momentum Explain the Smart Money Effect? The Journal of Finance, 59 (6), 2605-2622.

Sirri, E. R. and Tufano, P. (1998). Costly Search and Mutual Fund Flows. The Journal of Finance, 53 (5), 1589-1622.

Stahl, F., Heitmann, M., Lehmann, D. R. and Neslin, S. A. (2012). The impact of brand equity on customer acquisition, retention, and profit margin. Journal of Marketing, 76 (4), 44-63.

Sundar, A. and Noseworthy, T. J. (2014). Place the Logo High or Low? Using Conceptual Metaphors of Power in Packaging Design. Journal of Marketing, 78 (5), 138-151.

Tuominen, P. (1999). Managing brand equity. Lta, 1 (99), 65-100.

Walther, T. (2015). Key Investor Documents and their Consequences on Investor Behavior. Journal of Business Economics, 85 (2), 129-156.

Weber, E. U., Siebenmorgen, N. and Weber, M. (2005). Communicating Asset Risk: How Name Recognition and the Format of Historic Volatility Information Affect Risk Perception and Investment Decisions. Risk Analysis, 25 (3), 597-609. 


\section{Appendix}

\section{A Figures and Tables}

Table 3: Fund characteristics.

\begin{tabular}{lcrrrrc}
\hline \hline $\begin{array}{l}\text { Mutual fund } \\
\text { ISIN) }\end{array}$ & $\begin{array}{c}\text { Asset } \\
\text { category }\end{array}$ & $\begin{array}{r}\text { Average return } \\
(2012-2014)\end{array}$ & $\begin{array}{c}\text { Front-end } \\
\text { load }\end{array}$ & $\begin{array}{c}\text { Back-end } \\
\text { load }\end{array}$ & $\begin{array}{c}\text { Annual } \\
\text { expense }\end{array}$ & $\begin{array}{c}\text { Risk } \\
(1-7)\end{array}$ \\
\hline $\begin{array}{l}\text { DekaBank EuroFlex Plus } \\
\text { (LU0192794724) }\end{array}$ & ABS & $9.2 \%$ & $1.5 \%$ & $0 \%$ & $0.46 \%$ & 3 \\
$\begin{array}{l}\text { Allianz GI Euro Bond Fund } \\
\text { (LU0212861099) }\end{array}$ & Bonds & $9.9 \%$ & $2.0 \%$ & $0 \%$ & $0.82 \%$ & 3 \\
$\begin{array}{l}\text { ACM Euro High Yield } \\
\text { (LU0119429891) }\end{array}$ & Bonds & $14.8 \%$ & $1.5 \%$ & $0 \%$ & $0.94 \%$ & 4 \\
$\begin{array}{l}\text { Pioneer Fund Euro Bond } \\
\text { (LU0496389064) }\end{array}$ & Bonds & $7.6 \%$ & $1.0 \%$ & $0 \%$ & $1.96 \%$ & 3 \\
\hline \hline
\end{tabular}

Notes: Average return is calculated for the years 2012, 2013 and 2014.

Table 4: Actual fund development.

\begin{tabular}{lrrrr}
\hline \hline & DekaBank & Allianz GI & ACM & Pioneer \\
\hline Return & $0.08 \%$ & $-3.57 \%$ & $1.10 \%$ & $-2.81 \%$ \\
Net return (incl. fees) & $-1.44 \%$ & $-5.53 \%$ & $-0.48 \%$ & $-3.93 \%$ \\
\hline \hline
\end{tabular}

Notes: The relevant investment horizon in our experiment is between 14 April 2015 and 12 May 2015 and 15 April and 13 May 2015, respectively.

Table 5: Robustness: cubic spline interpolation for expected value.

\begin{tabular}{|c|c|c|c|c|c|c|c|}
\hline \multirow[b]{2}{*}{ Variable } & \multirow[b]{2}{*}{ Treatment } & \multirow[b]{2}{*}{ Obs. } & \multirow[b]{2}{*}{ Mean } & \multirow[b]{2}{*}{ Median } & \multirow[b]{2}{*}{ Variance } & \multicolumn{2}{|c|}{$\mathrm{P}$-value } \\
\hline & & & & & & $\begin{array}{c}\text { Permutation } \\
\text { test }\end{array}$ & $\begin{array}{c}\text { Brown-Forsythe } \\
\text { test }\end{array}$ \\
\hline Expected & Original & 87 & 101.88 & 101.77 & 2.54 & 0.614 & 0.889 \\
\hline value & Neutral & 95 & 101.76 & 101.56 & 2.61 & & \\
\hline
\end{tabular}

Notes: Expected value is derived from 100 draws from a subjective probability distribution based on Hyman-filtered cubic spline interpolation. 


\section{B Questionnaire}

\begin{tabular}{|r|r|r|r|r|}
\hline Factors & original & neutral & Total & rank-sum p \\
\hline Document quality & $3.4(4)$ & $3.67(3)$ & $3.54(3)$ & .2943 \\
Brand & $2.67(5)$ & $2.39(5)$ & $2.52(5)$ & .1441 \\
Experience with firm & $1.97(6)$ & $2.13(6)$ & $2.05(6)$ & .7674 \\
Cost & $3.41(3)$ & $3.56(4)$ & $3.49(4)$ & .4873 \\
Historical data & $5(1)$ & $5.13(1)$ & $5.07(1)$ & .3158 \\
Risk indicator & $4.82(2)$ & $4.86(2)$ & $4.84(2)$ & .8777 \\
\hline Background Risk & & & & \\
\hline Greek debt crisis & 3.38 & 3.16 & 3.26 & .3275 \\
EZB monetary policy & 3.43 & 3.08 & 3.25 & .1018 \\
DAX development & 3.05 & 3.05 & 3.05 & .9519 \\
\hline
\end{tabular}

Table 6: Factors important for decision. Answers on a 6-point likert scale ranging from 'not important at all' to 'very important'. Cardinal rank in parentheses. Ranksum shows p-value of a Mann-Whitney ranksum test.

\begin{tabular}{|l|l|l|l|l|}
\hline & original & neutral & Total & rank-sum p \\
\hline $\begin{array}{l}\text { Would you change your decision if ad- } \\
\text { vised by a professional? }\end{array}$ & 5.41 & 5.37 & 5.39 & .7838 \\
\hline $\begin{array}{l}\text { Information was sufficient to make an } \\
\text { investment decision. }\end{array}$ & 2.98 & 2.89 & 2.93 & .9862 \\
\hline I did not understand the information. & 2.87 & 2.81 & 2.84 & .9655 \\
\hline $\begin{array}{l}\text { How competent do you think you are } \\
\text { in making investment decisions? }\end{array}$ & 2.74 & 2.32 & 2.52 & .0567 \\
\hline $\begin{array}{l}\text { How sure are you that you made the } \\
\text { right investment decision? }\end{array}$ & 3.03 & 2.62 & 2.82 & .0615 \\
\hline
\end{tabular}

Table 7: General debriefing questions. Answers on a 7-point likert scale. 


\begin{tabular}{|l|l|l|l|l|}
\hline & original & neutral & Total & rank-sum p \\
\hline Useful & 4.03 & 3.85 & 3.94 & .242 \\
\hline Informative & 4.05 & 4.15 & 4.1 & .6184 \\
\hline Reliable & 4.43 & 4.31 & 4.36 & .4033 \\
\hline Credible & 4.22 & 4.18 & 4.2 & .6697 \\
\hline
\end{tabular}

Table 8: Impression of the information sheets. Answers on a 6- point likert scale ranging from 'do not agree' to 'do fully agree'.

\begin{tabular}{|l|l|l|l|l|l|}
\hline & original & neutral & Total & rank-sum p & $\chi^{2}$ \\
\hline Legal document & $64 \%$ & $77 \%$ & $71 \%$ & .065 & .064 \\
\hline $\begin{array}{l}\text { Risk indicator not reliable indica- } \\
\text { tion for future development }\end{array}$ & $53 \%$ & $65 \%$ & $59 \%$ & .0901 & .089 \\
\hline Total loss possible & $47 \%$ & $55 \%$ & $51 \%$ & .3062 & .305 \\
\hline $\begin{array}{l}\text { Past development does not con- } \\
\text { tain front-end load }\end{array}$ & $43 \%$ & $35 \%$ & $38 \%$ & .2818 & .280 \\
\hline $\begin{array}{l}\text { Past development not reliable in- } \\
\text { dication for future development }\end{array}$ & $80 \%$ & $81 \%$ & $81 \%$ & .9195 & .919 \\
\hline Liability-relevant & $38 \%$ & $34 \%$ & $36 \%$ & .5514 & 0.550 \\
\hline $\begin{array}{l}\text { Past development contains yearly } \\
\text { data }\end{array}$ & $92 \%$ & $98 \%$ & $95 \%$ & .0656 & .065 \\
\hline
\end{tabular}

Table 9: Correct answers to questions about the information document in percent. 


\section{Treatments}
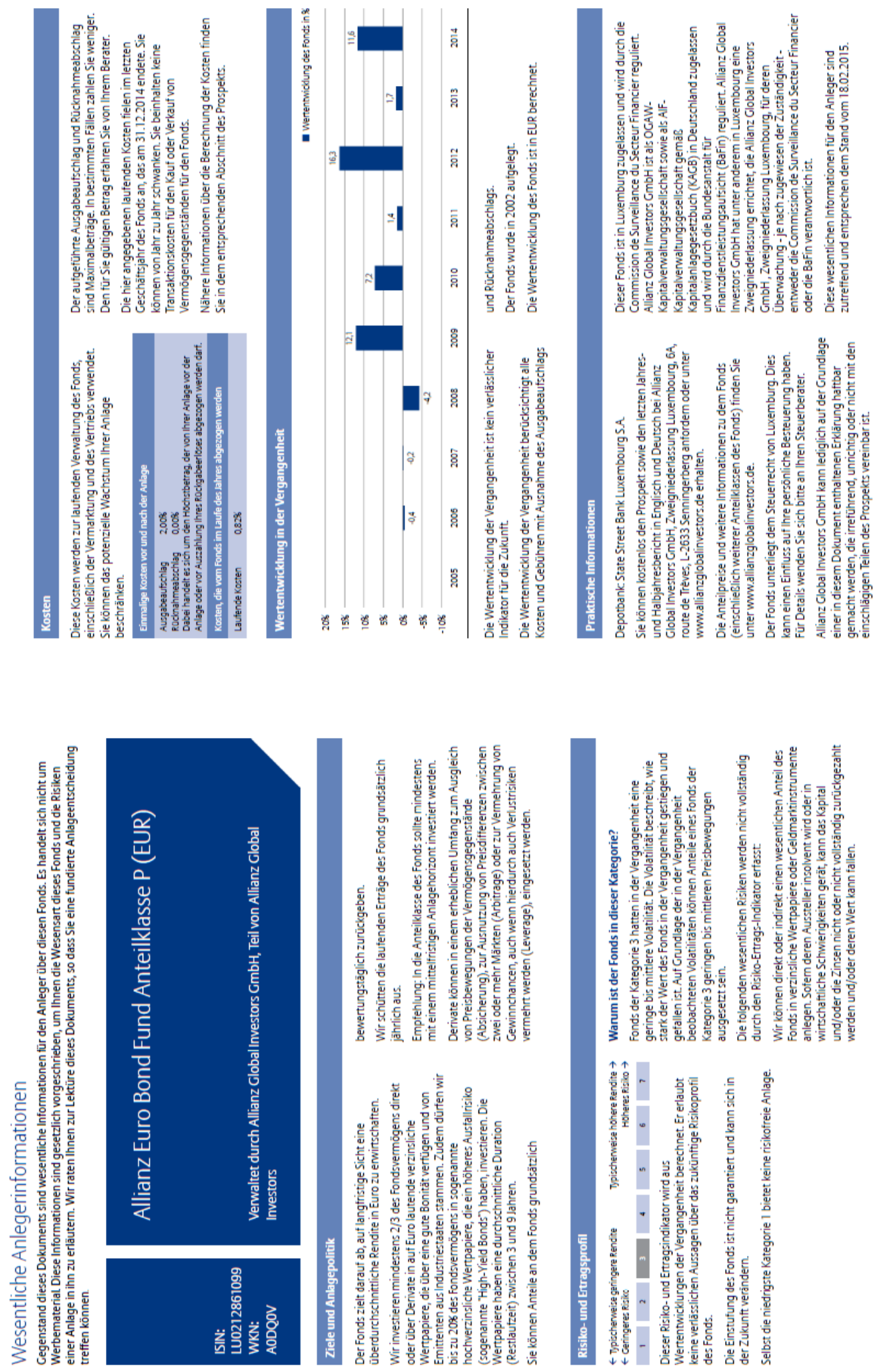

Figure 7: Treatment original for Allianz. 

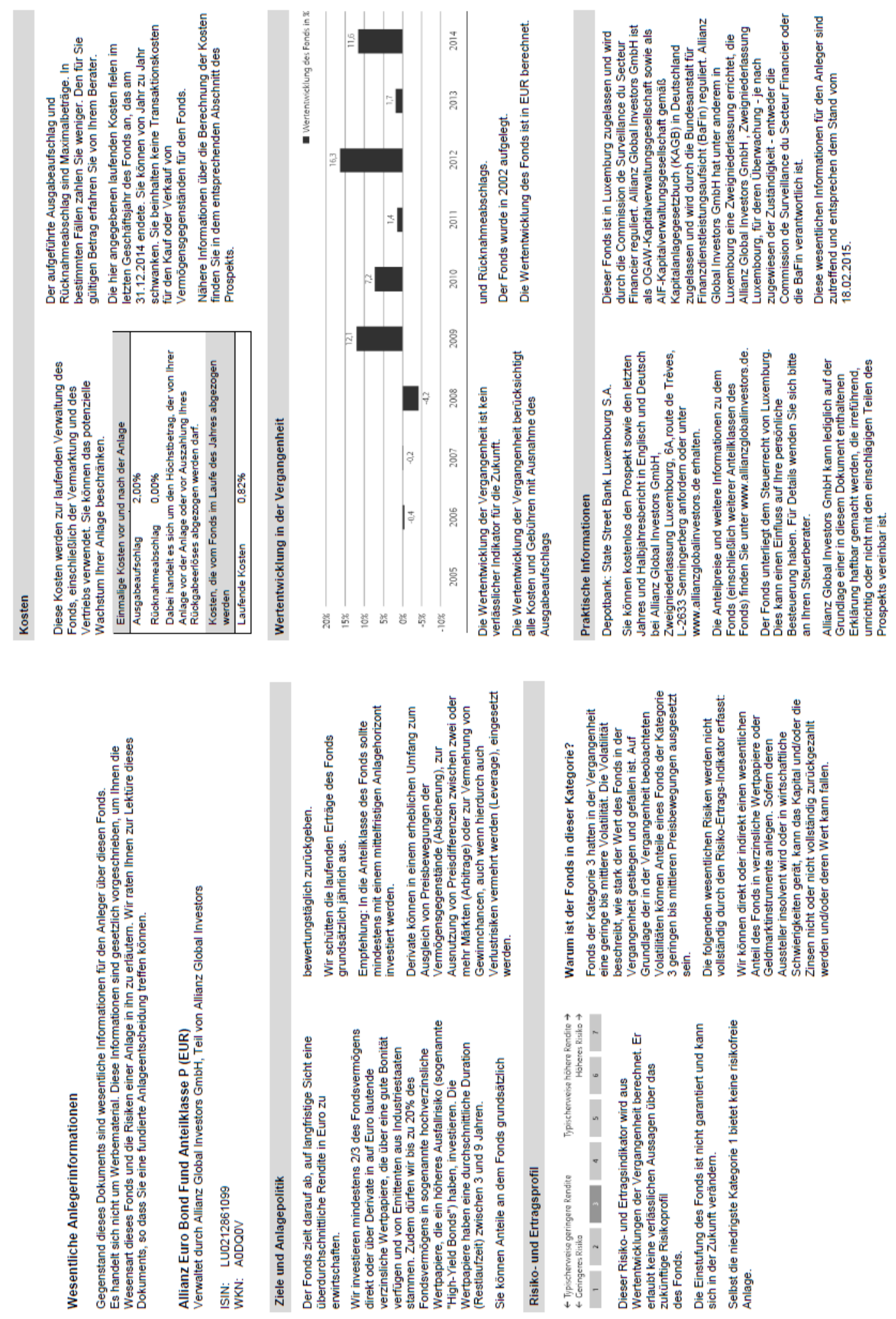

Figure 8: Treatment neutral for Allianz. 


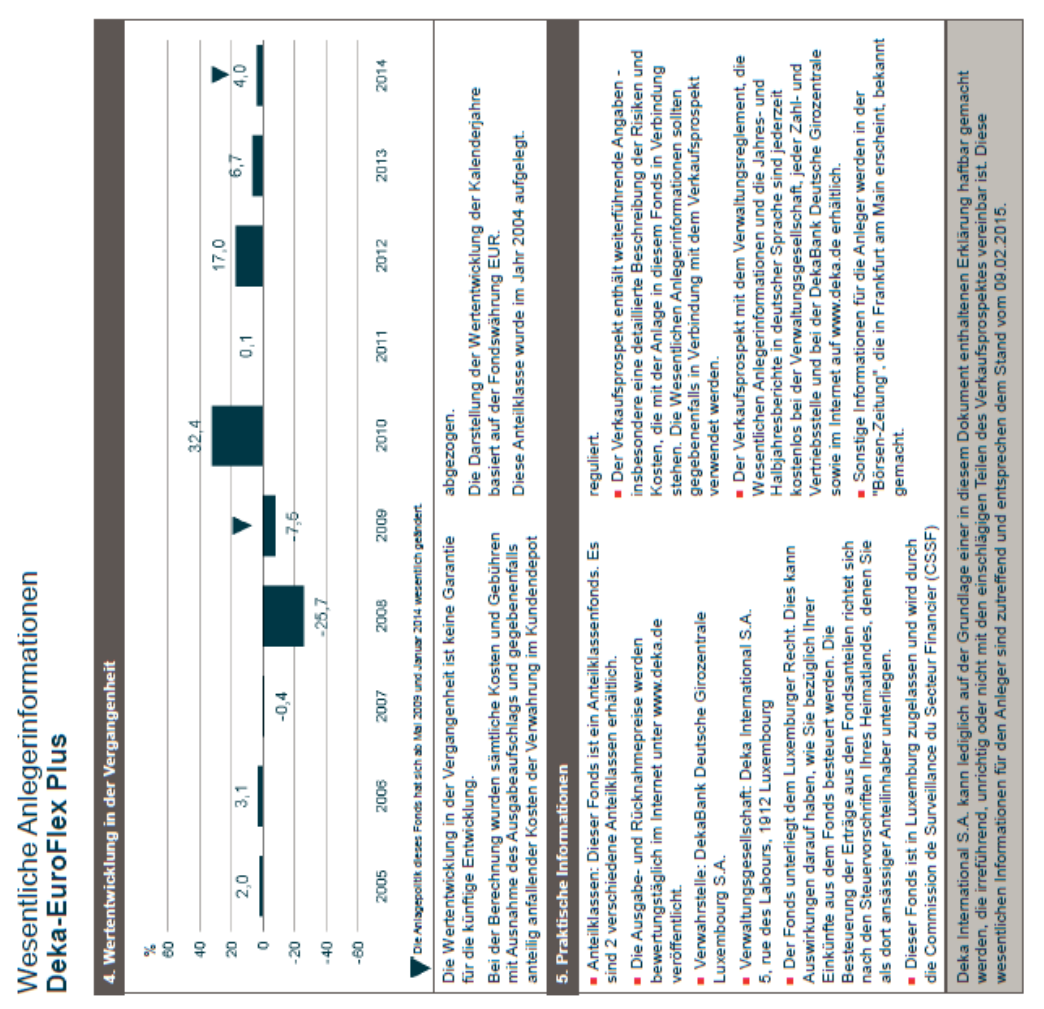

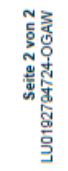

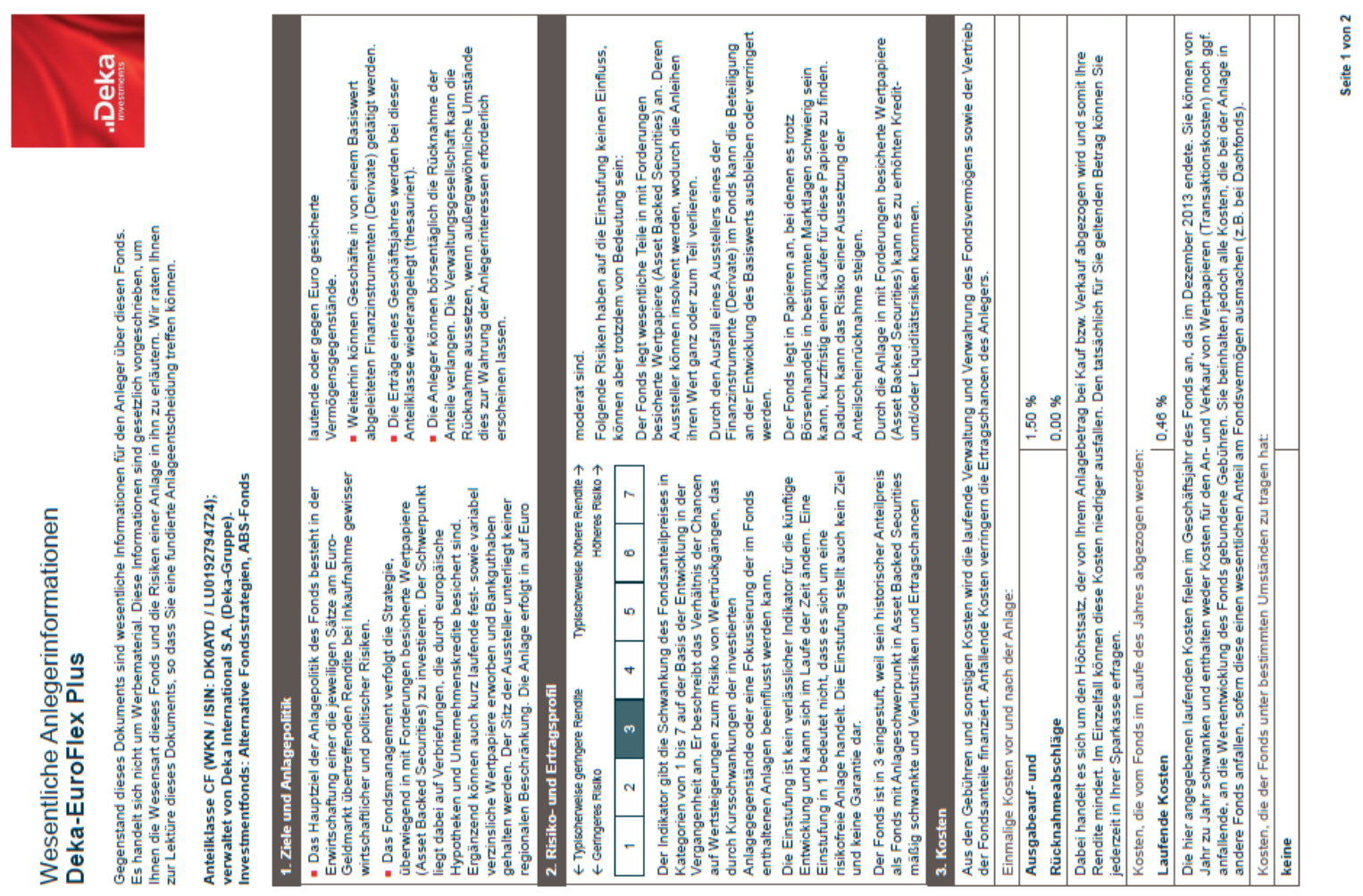

Figure 9: Treatment original for DekaBank. 

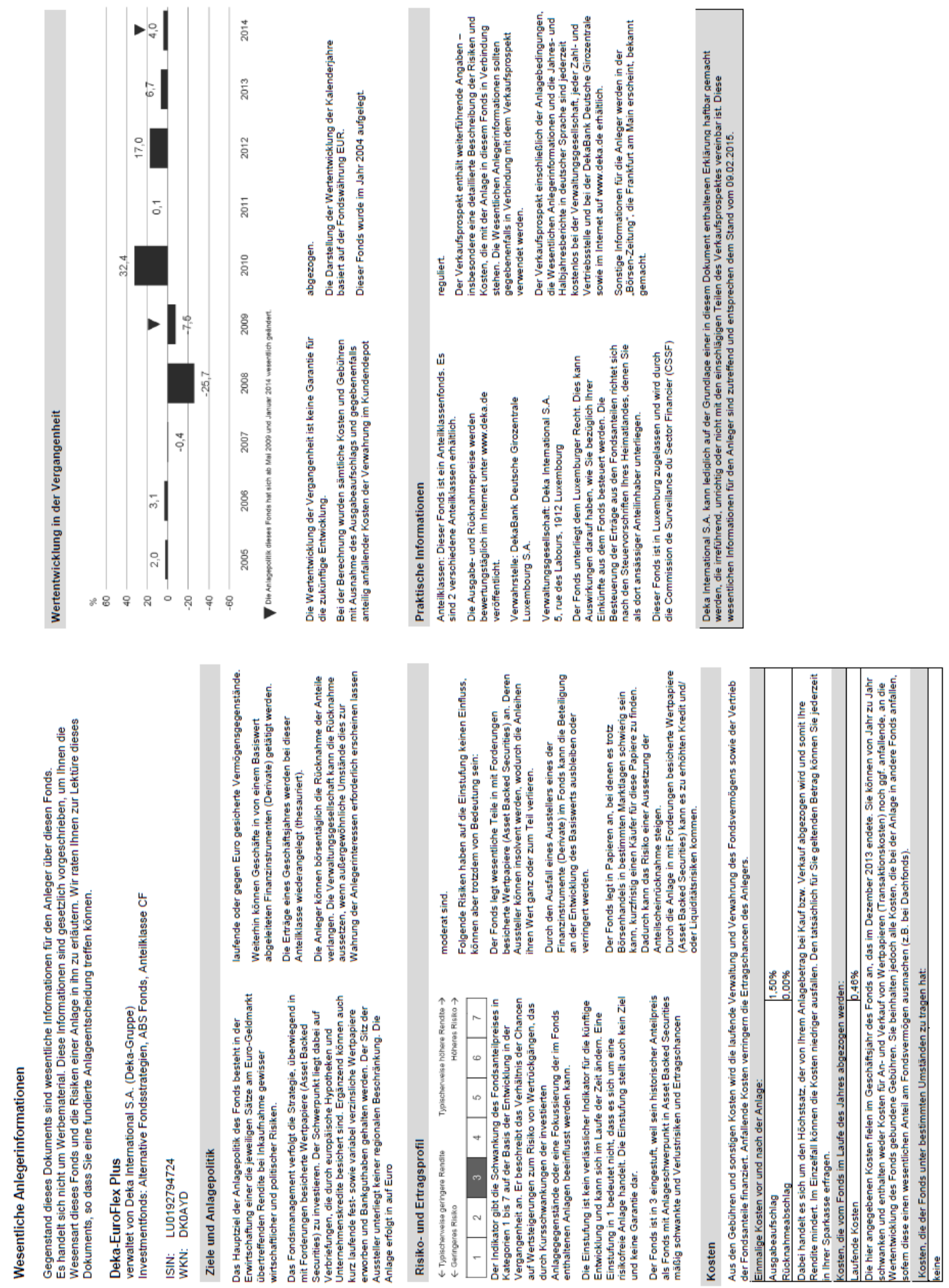

Figure 10: Treatment neutral for DekaBank. 

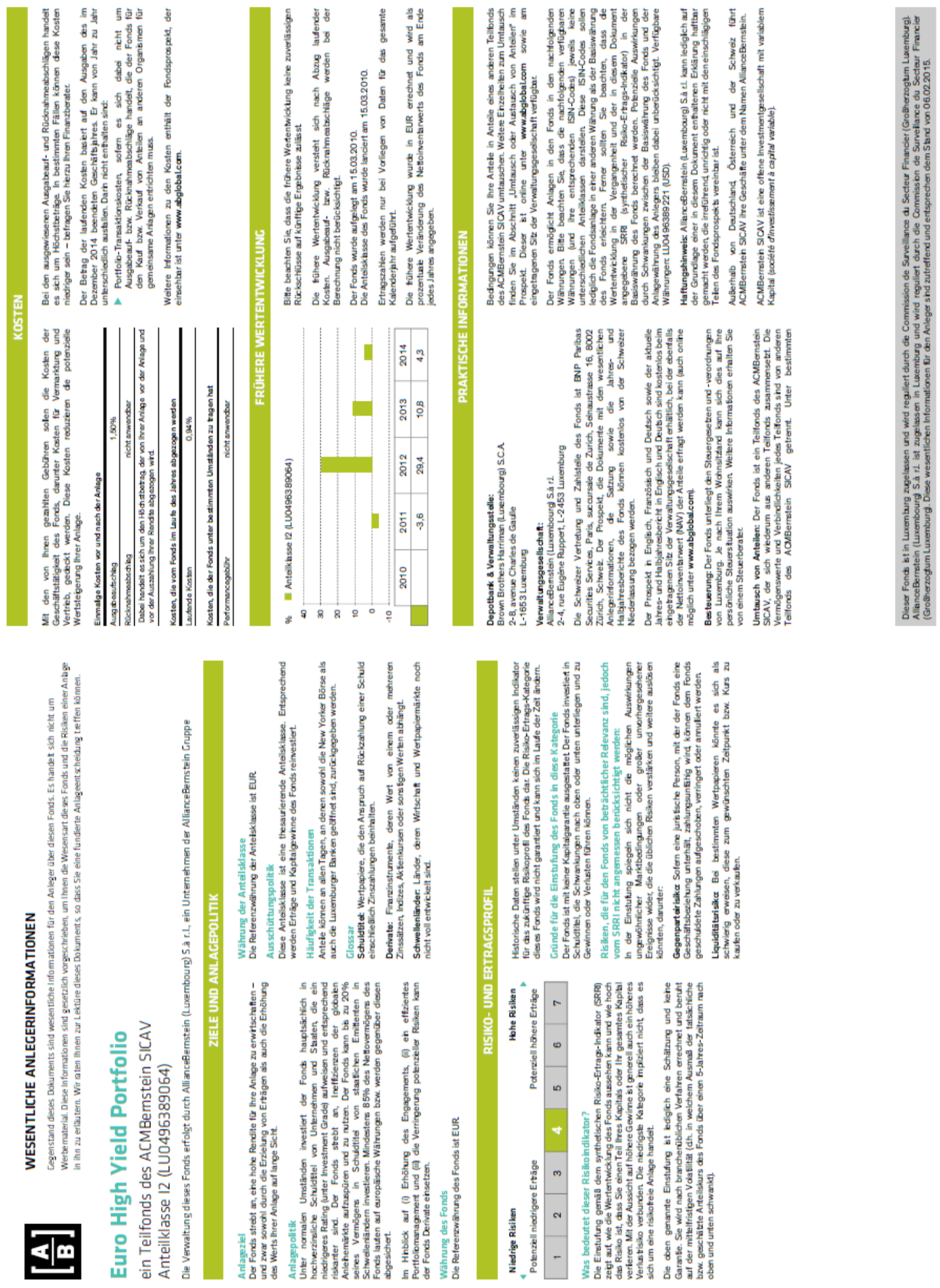

Figure 11: Treatment original for ACM. 

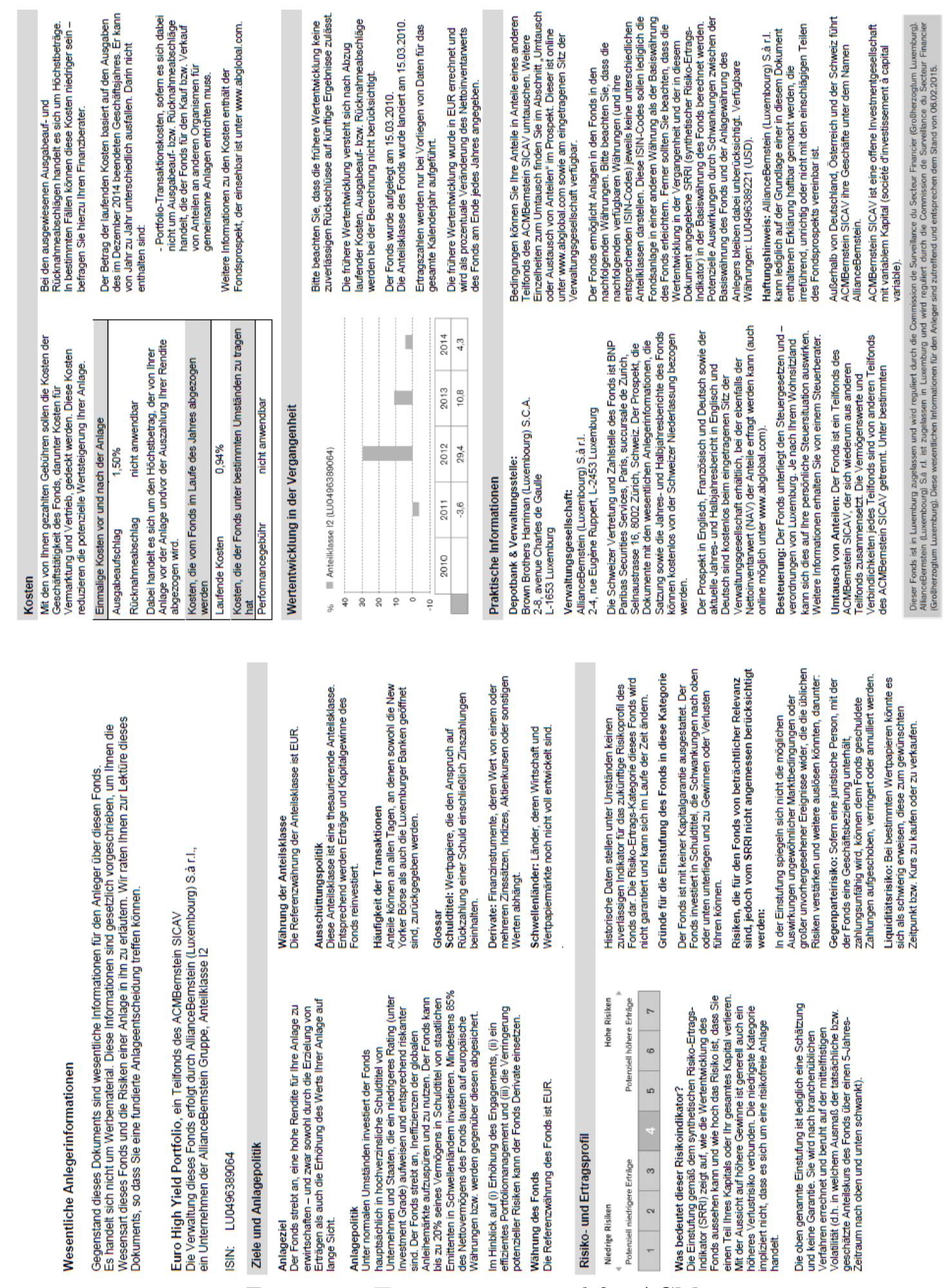

Figure 12: Treatment neutral for ACM. 

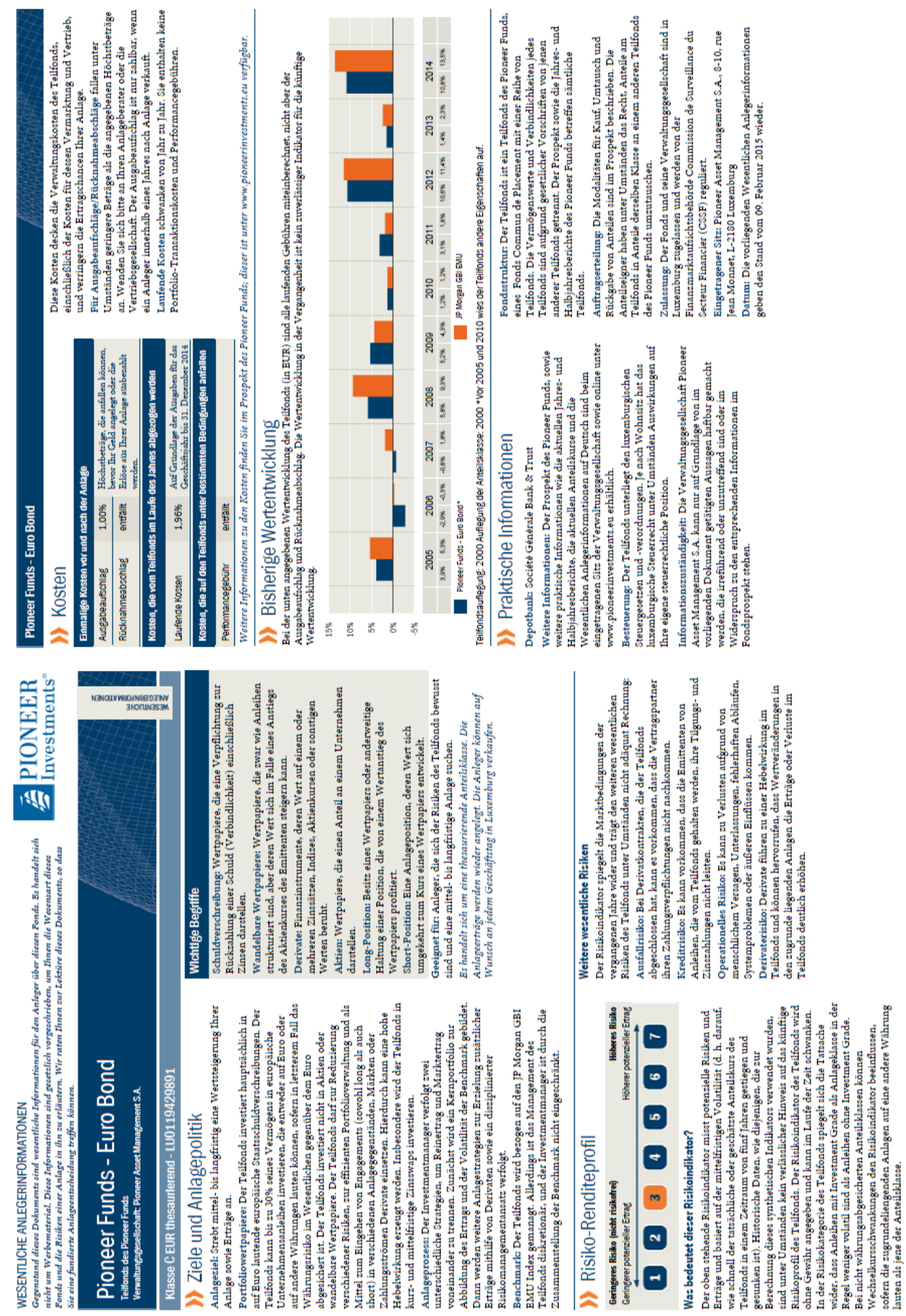

Figure 13: Treatment original for Pioneer. 

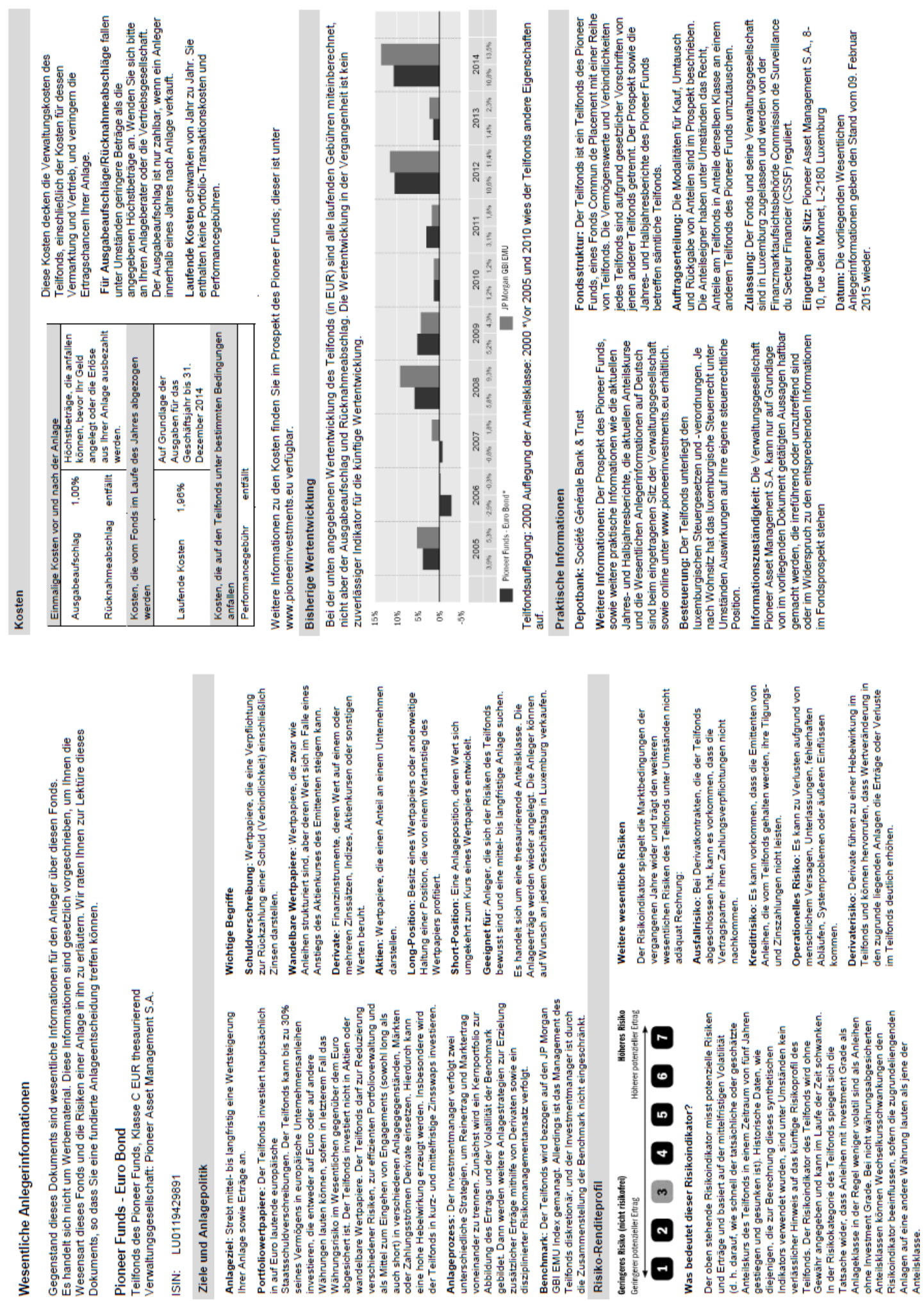

Figure 14: Treatment neutral for Pioneer. 


\section{Screens}

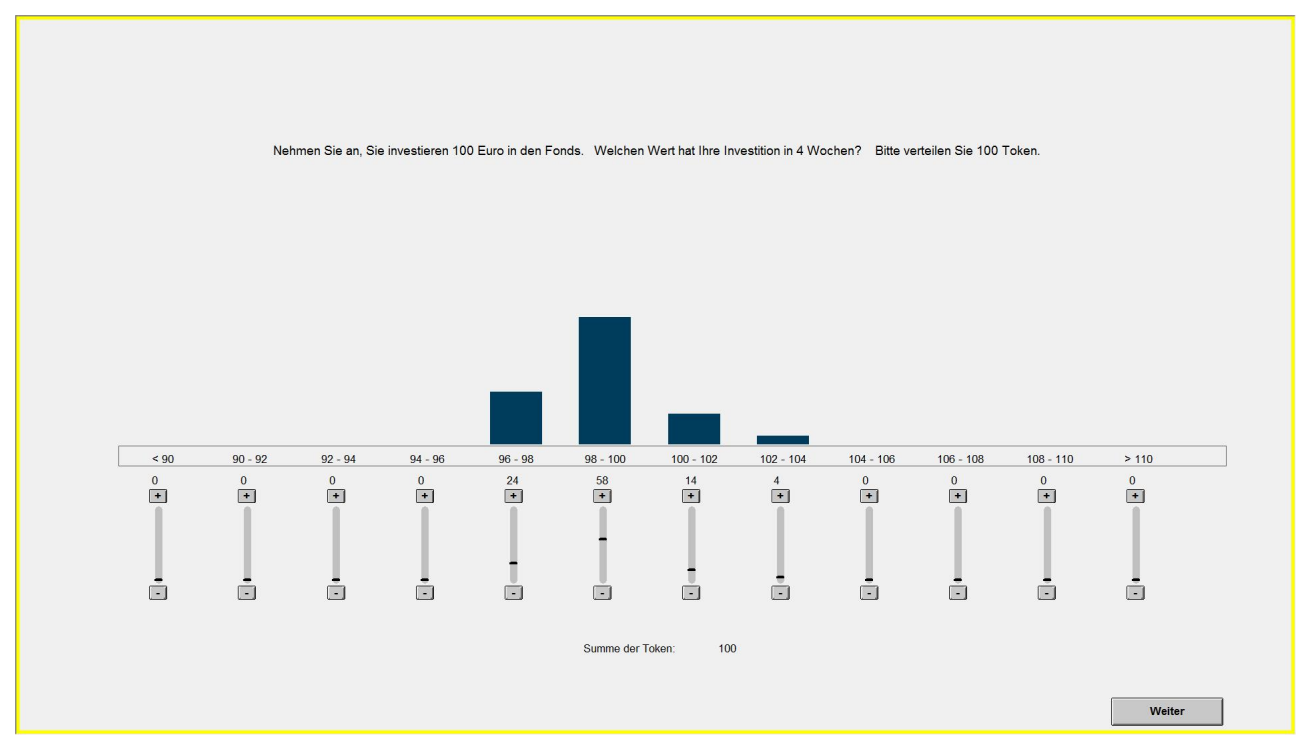

Figure 15: Screen: belief stage.

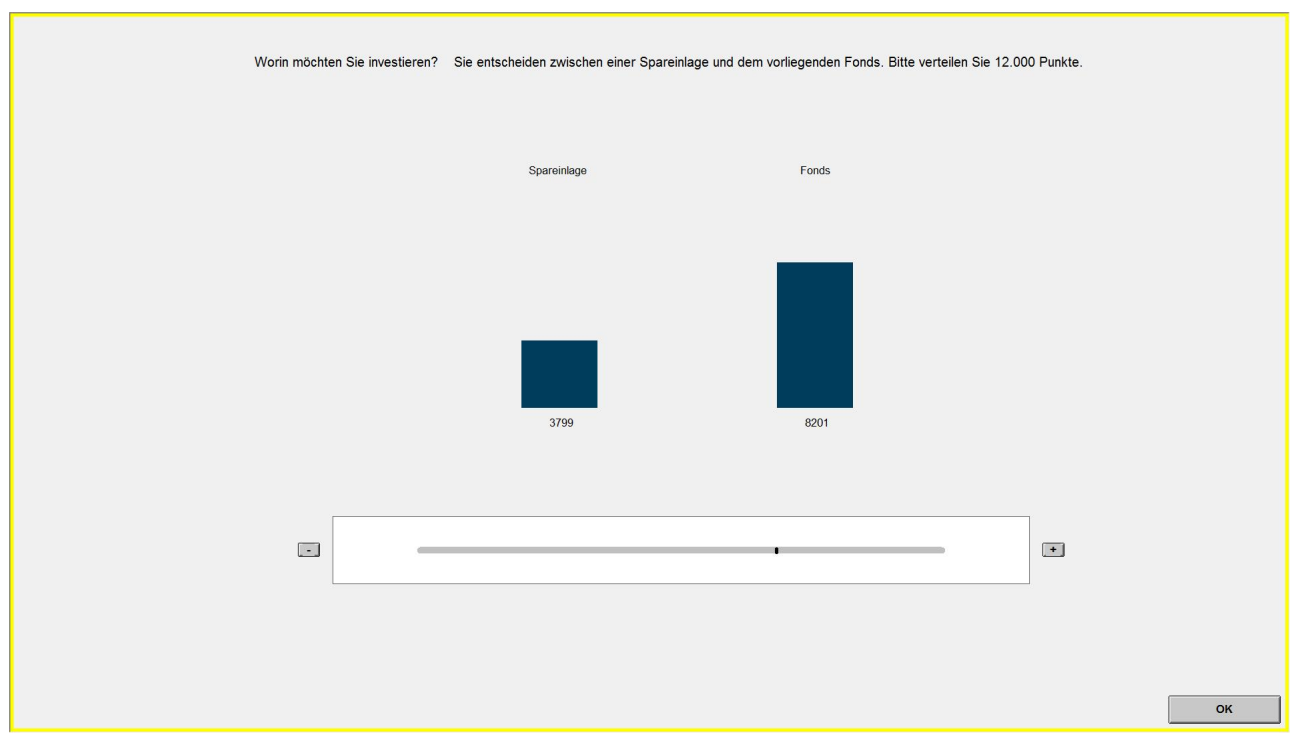

Figure 16: Screen: investment stage. 


\title{
E Instructions
}

\section{(English version translated from German)}

\author{
Welcome to our experiment!
}

You are going to take part in an economic study. This study is part of a project financed by the Max Planck society. If you read the following explanations carefully, you will be able to earn a substantial sum of money. It is therefore crucial that you read these explanations carefully. During the experiment it is prohibited to use electronic devices. Please use only the experimental program on the computer. During the experiment there shall be absolutely no communication between participants. If you have any questions, please raise your hand. We will then come over to you. Any violation of these rules means you will be excluded from the experiment and from any payments.

For participating in the experiment you receive a show-up fee of 5 euros. Additionally, you will be able to earn money. Your payment depends on your decisions, the future development of an investment and on chance. Instructions are identical for all participants. The procedure and the payment details are described below.

\section{Procedure}

- Practicing period

- 4 rounds with two tasks each

- Questionnaire

- 1. payment: directly after the experiment

- 2. payment: via bank transfer at the 18 th of may 2015

Before the experiment starts you will have the opportunity to practice and to get used to the decision environment.

The experiment consists of 4 rounds. Each round consists of two tasks: an estimation task and an investment task. In the end one out of two tasks in one round will be chosen randomly and is then relevant for your payment. Since you do not know which task is going to be chosen for payment, you should decide carefully. Payment consists of two parts. The second part of the payment will be paid 4 weeks after the experiment.

During the experiment we will not calculate in euro, but instead in points. The total number of points you earn in the course of the experiment will be transferred into euro at the end, at a rate of

$$
800 \text { points }=1 €
$$

Following the tasks, we ask you to answer a questionnaire. Please also answer these questions carefully. After you have finished the experiment, you receive your payment for today and leave the laboratory. 


\section{Task 1}

In the first task, we ask you to predict the value of an investment into a fund in four weeks. You are dealing with real-world funds in this experiment. Your prediction will be compared to the actual development of the fund investment. Your payment depends on your performance at this prediction.

We calculate your payment four weeks after you have made your prediction. Precisely, we calculate how much an investor would actually get back from a 100 euro investment into the fund. Such an investor takes costs and expenses on a monthly level into account. We assume that you invest today $14 / 04 / 2015(15 / 04 / 2015)$ at $5: 59 \mathrm{pm}$ in shares of the fund. We further assume that shares are sold on Wednesday 13/05/2015 (Tuesday 12/04/2015) at 5:59pm. Your prediction is compared to the actual value from selling this investment.

\section{What is a fund?}

A fund is a way of investing money. An investment company collects money of investors, pools it and invests it in one or more areas of investment. Shares may be traded each trading day. Money is invested according to certain investment guidelines, e.g. in stocks, bonds, in the money market or in real estate. Usually funds need to spread risks when investing. That is, a fund cannot invest everything in one stock or one real estate property.

The selection of funds in this experiment is no recommendation for investments outside this experiment. This research is not financed by these fund companies. Fund companies do not get data from this study.

You will get the opportunity to read information about the funds. This is actual information from the real-world fund. The two-page information will be distributed before each round. You can choose between different intervals in your prediction. Specifically, you can distribute 100 tokens between up to 12 intervals. You determine the number of tokens by switching the slider with the cursor. Tokens are displayed as bars. Please consider the following example. The picture below shows the decision screen of the computer.

\section{Decision screen}

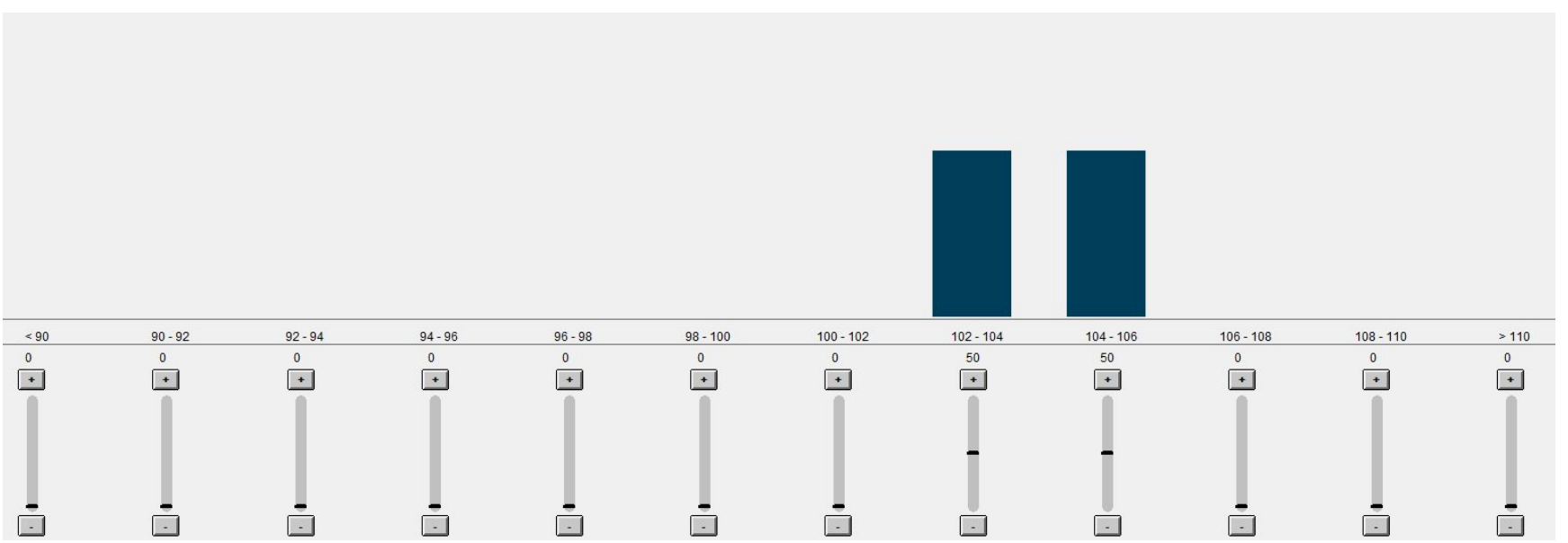


Assume you are investing 100 euros today into the fund. Please answer the following question:

What will be the value of your investment after 4 weeks?

In other words, please predict the likelihood that the actual value of your investment will be in the interval. Inflation can be disregarded. Assume for instance, that your are completely sure that the future value from the investment will lie in the interval between 102 and 104 euros. Then, you would answer the question above by distributing 100 tokens in the interval "102-104". If you would think it is equally likely that the future value will lie between 102 and 104 or between 104 and 106 euros, then you would distribute, as in the example above, 50 tokens in the interval "102-104" and 50 tokens in the interval "104-106".

In the following, we explain precisely the calculation of your payment.

First, we scale the number of tokens to 1 , i.e. we divide them by 100 . That is, 30 tokens correspond to $30 / 100=0,3 ; 40$ tokens correspond to $40 / 100=0,4$ and so on. Second, we determine the interval which contains the actual value. We call this the target interval. Third, we calculate your payment based on three parts:

- The deviation of your estimate from the actual value is calculated as follows:

(tokens in target interval -1$)^{2}$

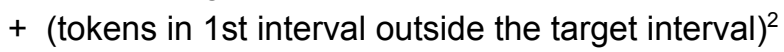

+ (tokens in 2nd interval outside the target interval) $^{2}$

$+\ldots$

+ (tokens in 11th interval outside the target interval) $^{2}$

- A random number between 0 and 1 is drawn.

- If your deviation is smaller or equal to the random number, then you receive 16.000 points. If your deviation is larger than the random number, then you receive 0 points. The smaller your deviation, the larger is your chance to receive 16.000 points.

Please consider the following 3 examples to illustrate how your payment is calculated.

Assume for instance, that your think it is likely that the future value will lie between 102 and 104 euros. Further, you think it is less likely that the future value will lie between 104 and 106 euros. You think it is even less likely that the future value will lie between 106 and 108 euros. Then, you distribute 60 tokens in the interval „102-104“, 30 tokens in the interval „104-106“, 10 tokens in the interval „106-108“ and 0 tokens in the remaining intervals.

1. Example: If the actual value after 4 weeks is 103 euros, then your deviation is calculated as follows $(0,6-1)^{2}+\left(0,3^{2}+0,1^{2}\right)=0,26$.

The deviation is 0,26 . The payment is:

If $0,26 \leq$ random number between 0 and 1 , then you receive 16.000 points.

If $0,26>$ random number between 0 and 1 , then you receive 0 points. 
2. Example: If the actual value after 4 weeks is 105 euros, then your deviation is calculated as follows $(0,3-1)^{2}+\left(0,6^{2}+0,1^{2}\right)=0,86$.

The deviation is 0,86 . The payment is:

If $0,86 \leq$ random number between 0 and 1 , then you receive 16.000 points.

If $0,86>$ random number between 0 and 1 , then you receive 0 points.

Next, assume you are distributing 12 tokens on the interval „102-104“ and equal amount of tokens (8 tokens) on each other interval.

3. Example: If the actual value after 4 weeks is 103 euros, then your deviation is calculated as follows $(0,12-1)^{2}+\left(0,08^{2}+0,08^{2}+0,08^{2}+0,08^{2}+0,08^{2}+0,08^{2}+0,08^{2}+0,08^{2}+0,08^{2}+0,08^{2}+0,08^{2}\right)=0,93$.

The deviation is 0,93 . The payment is:

If $0,93 \leq$ random number between 0 and 1 , then you receive 16.000 points.

If $0,93>$ random number between 0 and 1 , then you receive 0 points.

Attention: The numbers of tokens and expressions such as "likely" or "very likely" in the above examples have been chosen arbitrarily. They are no guidance for your decisions in the experiment. The examples indicate that your chance to earn 16.000 points increases with the precision of your estimate.

You may ask yourself why we selected such a calculation rule as above. The reason is, that under such a calculation rule, your expected payment is highest if you distribute tokens according to your true belief.

\section{Task 2}

In the second task, we ask you to make an investment decision. You are endowed with 12.000 points. You have the opportunity to invest in the following investments:

- into the fund

- into a savings account with interest rate of $0,1 \%$ per year

Please answer the following question: How many of the 12.000 points are you investing into the funds and how many in the savings account? Please decide by switching the slider below the two options. We calculate your payment based on the actual value of your investments after 4 weeks.

That is, we calculate how much an investor would actually get back from a 100 euro investment into the investments. Such an investor takes costs and expenses on a monthly level into account. We assume that you invest today $14 / 04 / 2015(15 / 04 / 2015)$ at $5: 59 \mathrm{pm}$ in shares of the fund. We further assume that shares are sold on Wednesday 12/05/2015 (13/05/2015) at 5:59pm. 


\section{Payment}

Your payment consist of 2 parts. Today, you receive the first part right after the experiment. You will receive the second part after 4 weeks. After the experiment, one out of four rounds is randomly selected for you by the computer. Then, one out of two tasks is randomly selected for you. This task is relevant for your payment in 4 weeks.

You will receive your payment either by bank transfer or cash. Please choose one of the payment options.

If you choose bank transfer, then you may type your IBAN in the corresponding field on the screen after the experiment has started. Make sure you have your IBAN with you. Your payment details are treated as confidential. We only use them to make sure you will receive your payment. Of course, data and publication of results are anonymized.

If you choose the cash payment, then we would ask you to type the six-digit code at your place into the screen once the experiment is started. Payment is only possible based on this code. Therefore, you should store it safely. Payment will take place on Monday 18/05/2015 (2:00-4:00 pm) at the Max Planck Institute for Research on Collective Goods (Kurt-Schumacher-Str. 10, 53113 Bonn).

Do you have any questions? Please answer the control questions.

Thank you for participating in the experiment! 


\section{Control questions}

1. What are the parts of the total payment?

2. How many rounds and tasks are randomly selected for payment?

3. Assume you distribute 100 tokens in task 1 to the interval „102-104“ and 0 tokens to the others.

a. How is the payment calculated in task 1 , if the actual value after 4 weeks is 103 and the random number is 0,7 ?

b. How is the payment calculated in task 1, if the actual value after 4 weeks is 107 and the random number is 0,7 ? 